\title{
El complejo mundo de la retórica mágica: una mirada más allá de la coacción ${ }^{1}$
}

\author{
Miriam Blanco Cesteros ${ }^{2}$
}

Recibido: 10 de febrero de 2017 / Aceptado: 11 de diciembre de 2017

Resumen. En la religión greco-romana, los dioses podían escuchar o no la plegaria, acudir o no al ritual, pero generalmente su colaboración estaba garantizada si el ritual se realizaba correctamente, libre de impurezas que lo invalidaran y los dioses eran apropiadamente invocados. Sin embargo, en el contexto de la práctica mágica, donde el agente ritual -el mago o la persona que realiza el rito mágicoactuaba movido por intereses egoístas fuera de un contexto religiosamente sancionado, la colaboración divina no estaba garantizada. Entonces, ¿cómo se lograba esta? En este artículo mi propósito es realizar un elenco de los recursos retóricos y estrategias persuasivas utilizadas en el diálogo con los dioses por los practicantes de magia con el fin de ilustrar el rico abanico de procedimientos empleados en el lógos mágico para lograr el apoyo divino.

Palabras clave: retórica, pragmática, magia, papiros mágicos griegos.

\section{[en] The complex World of Magical Rhetoric: a Glance beyond Coercion}

\begin{abstract}
In the Greco-Roman religion, gods could listen or not a prayer, attend or not the ritual, but usually there were not problems if the ritual was made correctly, without impurity that could invalidate it and the worshiper invoked gods appropriately. However, in a magical praxis in which the magical practitioner acted for selfish aims outside from normalized religious boundaries, the collaboration of the gods was not guaranteed. Thus, how do magicians got the divine cooperation? My aim in this paper will be to illustrate the rich variety of rhetorical resources and persuasive strategies used in the dialogue with gods by magical practitioners in order to obtain the divine help.
\end{abstract}

Keywords: rhetoric, pragmatic, magic, Greek magical papyri.

1 Este artículo ha sido elaborado en el marco del proyecto de investigación FFI2014-57517-P, financiado por el MINECO, y está basado en una comunicación (inédita), de título "The rhetoric of magic and the persuasion of the Gods", presentada en el Congreso Internacional de Jóvenes Investigadores Europaeum Classics Colloquium: Poetry, Oratory, Rhetoric, Persuasion: the Power of Word in Ancient Times, organizado por el Europaeum en la Universidad Pompeu Fabra entre el 5 y el 7 de noviembre de 2015.

En el presente estudio se han empleado las siguientes abreviaturas: DTAud=Audollent (1904); h.Mag.= Himno Mágico (estas composiciones son citadas por el número que poseen en el catálogo que se encuentra al final del 2 vol. de Preisendanz 1973-1974²); $L M P G=$ MUÑOZ DELGADO (2001); $P G M=$ Preisendanz (1973-1974²), por convención, citados por el número que poseen en dicha edición; $S G G=$ Mastrocinque (2003-2007); $S M=$ Daniel - Maltomini (1990-1992), por convención, citados por el número en que son recogidos en esta edición; ThesCRA = Thesaurus cultus et rituum antiquorum (2005-2012). En cuanto a las traducciones, a menos que se indique lo contrario, son propias.

$2 \quad$ E-mail: miriam.blan@hotmail.com 
Sumario. 1. Recursos de naturaleza no retórica. 2. Recursos de naturaleza retórica. 3. La sobreacumulación de recursos. 4. Conclusiones.

Cómo citar: Blanco Cesteros, M. (2018) El complejo mundo de la retórica mágica: una mirada más allá de la coacción, en Cuadernos de Filología Clásica. Estudios griegos e indoeuropeos 28, 171-193.

El estudio de los testimonios de la práctica mágica ${ }^{3}$ que nos han llegado desde la antigua Grecia y Roma - esencialmente, testimonios de magia "aplicada"-_, y el Egipto imperial romano -testimonios de magia "aplicada" y manuales de prácticas mágicas $^{5}-$, muestra que todo acto mágico (predicción del futuro, obtención de conocimiento, bienes, fuerza, victoria, salud, amor, etc.) se obtenía por intercesión divina, siendo los dioses y otras entidades de naturaleza similar los garantes últimos de la mayoría de procedimientos mágicos ${ }^{6}$. El poder divino se configura así como la quintaesencia de la magia del mundo mediterráneo de época greco-romana ${ }^{7}$, motivo por el que desempeñaba en esta una importancia "radical" y una parte no desdeñable de los actos mágicos giraban en torno a los dioses: cómo ganarse a las potencias divinas para que cumplieran las peticiones, cómo dominarlas o, incluso, protegerse de ellas. Por otra parte, el examen de los manuales de prácticas mágicas que nos han llegado muestra que, al menos en lo relativo a la magia greco-egipcia, los procedimientos empleados para lograrlo, en realidad, no difería en gran medida de la religión de la época en su

3 En este estudio he empleado el término "magia", por convención, para referirme al conjunto de prácticas y textos considerados usualmente como tales, pero plenamente consciente de los problemas asociados con su uso y el debate abierto entorno a su definición y su distinción de la categoría "religión" (cfr. bibliografía infra, n.7).

4 Se conocen bajo esta denominación los distintos productos textuales - filacterias, tablillas de maldición, etc. - y objetos -gemas, amuletos, figurillas de barro- elaborados en el marco de la realización de un ritual mágico. Sería demasiado largo enumerar aquí, por su gran cantidad, los artículos y ediciones individuales existentes, por lo que me limitaré a mencionar los principales corpora para su estudio: DT Aud., Gager (1992), Kotansky (1994) y $S G G$.

5 Se trata de recetarios escritos en papiro, en griego, demótico y copto, producidos en el contexto del Egipto de época Imperial romana por profesionales de la magia, que recogen y describen la realización de diversos hechizos y prácticas mágicas, motivo por el que en el ámbito anglosajón son conocidos también como magical handbooks. Por convención, sin embargo, se les conoce como "papiros mágicos", término que, no obstante, engloba también los testimonios de magia aplicada escritos en este material. Gran parte de los papiros mágicos griegos conocidos hasta 1924, fueron editados y recogidos por K. Preisendanz (hoy disponibles en una segunda edición revisada por A. Henrichs, $c f r$. Preisendanz 1973-1974²), con traducción al alemán; esta es la edición de referencia hasta el momento y en relación a la cual estos textos se citan como PGM, siglas que utilizaré en adelante para referirme a ellos. Posteriormente a la obra de Preisendanz, H.D. Betz (1992²) los tradujo al inglés incluyendo nuevos papiros griegos y los pasajes en demótico, excluidos de la obra de Preisendanz. Los papiros mágicos editados con posterioridad fueron recogidos y reeditados por R.W. Daniel y F. Maltomini en dos volúmenes titulados Supplementum Magicum (en adelante SM). En este momento, además, hay que destacar la existencia del proyecto "Transmission of Magical Knowledge in Antiquity. The Papyrus Magical Handbooks in Context”, coordinado por Ch. Faraone y S. Torallas y financiado por el Neubauer Collegium (Universidad de Chicago), para la reedición de $P G M$, cuya publicación está prevista para 2018.

6 En algunas recetas, sobre todo de carácter breve, se podría considerar que no hay una agencia divina, sino que funcionan por acción de las palabras mágicas empleadas en ellas (e.g. PGM VII 395, 411-16, 653ss., etc.), pero habría que examinar muy bien si esos nomina barbara y magica no están siendo considerados nomina divina.

7 Zografou (2016: 13-18). 
aspecto formal ${ }^{8}$, compartiendo con esta muchos de sus aspectos fundamentales: los actos constitutivos del ritual ${ }^{9}$, similares requerimientos de aptitud y pureza ${ }^{10}$ y su definición "émica" (los rituales se definen como "misterios", los practicantes de magia como "iniciados", "sacerdotes" y "suplicantes" "11). Sin embargo, no cabe duda de que, ya fuese por realizarse fuera de un contexto sancionado -de un templo o santuario-, o por la finalidad, en ocasiones penalizada tanto por las leyes humanas como divinas -como es el caso de la magia agresiva-, la colaboración de las divinidades no estaba garantizada y el poder divino que se intentaba invocar se convertía en un peligro para el mago ${ }^{12}$. ¿Cómo se lograba entonces la cooperación de la divinidad en la práctica mágica? La respuesta más frecuente suele ser "mediante coerción", rasgo que hasta hace poco se consideraba "definitorio" de la práctica mágica, pero que a la luz de los propios textos mágicos se demuestra en exceso simple y en absoluto válido, ya que la coacción era tan sólo uno de los múltiples recursos a los que la magia podía recurrir.

Para ilustrar la riqueza retórica y argumental de este ámbito, en este estudio he querido centrarme, dentro de los dos ejes sobre los que funcionaba el rito mágico ${ }^{13}$, en $\tau \grave{\alpha} \lambda \varepsilon \gamma o ́ \mu \varepsilon v \alpha$, con especial atención a los recursos empleados para conseguir la colaboración de la divinidad ${ }^{14}$.

8 Entrar aquí en el debate entre magia y religión en el mundo antiguo sería demasiado largo, por ello, baste decir que, frente a la oposición magia-religión de los estudios del siglo XIX y principios del XX, actualmente se ha comprobado que intentar definir "magia" en oposición a "religión" no sólo es difícil, sino muy relativo, ya que ambos conceptos varían significativamente dependiendo del punto de vista y contexto histórico-cultural desde el que sean examinados, vid. Fowler (1995), Faraone (1992²: 17-20), Bremmer (1999), Otto (2013). Por ello, los estudios actuales tienden a considerarlos dos posibilidades "retóricas" del diálogo humano con lo divino que forman parte del mismo continuum. Por este motivo, incluso, se ha abierto un debate en torno a la pertinencia del empleo del término "magia" como categoría, vid. Versnel (1991a), Bremmer (2002), Otto (2013).

9 En relación con la ofrenda, vid. Johnston (2000), Graf (2005), Zografou (2008). Para la "plegaria mágica", vid. Graf (1991; passim, pero en especial p. 194).

10 Un estudio detallado sobre la pureza y los requerimientos purificatorios de los rituales mágicos en Zografou (2018).

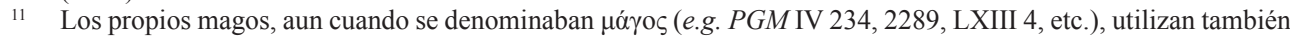

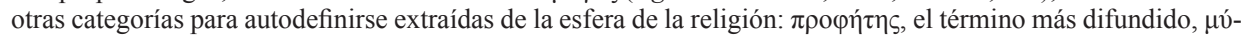

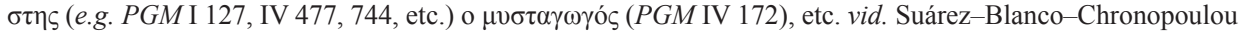
(2016: 208). La práctica mágica, por otro lado, es denominada "misterio" (e.g. PGM I 131, IV 476, etc.). Betz, quien se ha ocupado en detalle del estudio de este aspecto, afirma que "no hay distinción entre magia y culto mistérico", vid. Betz (1991) y (1992²: 258, n.2).

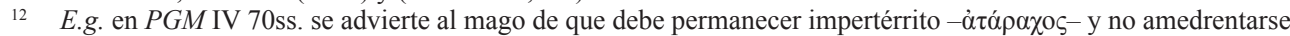

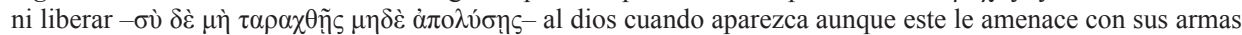

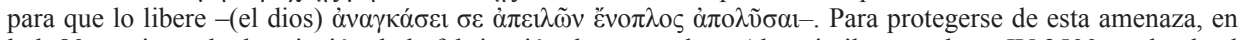
la 1.80 comienza la descripción de la fabricación de un amuleto. Algo similar sucede en IV 2500ss., donde el redactor de la práctica dice: "Hay un amuleto para que no te lance, pues a los que hacen estas cosas desprovistos de protección la diosa suele llevárselos por los aires y arrojarlos a la tierra desde lo alto". Un elenco y estudio detallado de estas advertencias en Chronopoulou (2015).

13 Para la magia greco-egipcia se han señalado dos partes constitutivas fundamentales: $\tau \hat{\alpha} \delta \rho \omega ́ \mu \varepsilon v \alpha$ y $\tau \dot{\alpha} \lambda \varepsilon \gamma o ́ \mu \varepsilon v \alpha$, es decir, lo que debe decirse durante el rito y lo que debe hacerse, aunque recientemente Graf (2015: 227-238) ha llamado la atención sobre un tercer vértice, $\tau \grave{\alpha} \gamma \rho \alpha \varphi o ́ \mu \varepsilon v \alpha$, lo que se debe escribir (y no siempre se pronuncia), reconociendo así la importancia de los dibujos y símbolos mágicos.

14 No trataré en este estudio, por lo tanto, los procedimientos que quedan fuera del ámbito de las estrategias persuasivas del diálogo empleadas para obtener la colaboración de los dioses, como los "actos de habla" cuando no implican una intención comunicativa entre el mago y el dios, sino un procedimiento "automático" de manipulación de la realidad en el que la pronunciación de la fórmula mágica, por su carácter performativo, bastaba para el cumplimiento del enunciado. Este fenómeno se produce, por ejemplo, en los $\kappa \alpha \tau \alpha \delta \varepsilon \sigma \mu o$ griegos y las defixiones latinas cuando se

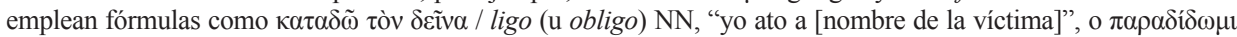

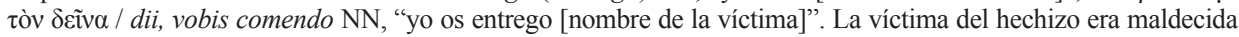
o entregada a los dioses (para su castigo) por acción de la propia fórmula, de forma idéntica al proceso por el que un objeto pasaba de la esfera profana a la propiedad de los dioses por efecto de su dedicación. Sobre este principio mágico, sus variantes y su funcionamiento pragmático-lingüístico, cfr. Kropp (2009: en especial pp.373-378) 
Existe un gran número de estudios que analizan de forma detallada estos procedimientos, pero, puesto que se centran en un solo fenómeno o una determinada categoría de estrategias, el complejo abanico de recursos persuasivos que se utilizaba queda, a mi entender, sesgado. Mi objetivo aquí no será, por tanto, hacer un análisis profundo de estos procedimientos, puesto que se ha escrito largo y tendido sobre muchos de ellos y no quiero repetir lo que otros han dicho, sino dar una visión panorámica de los mismos ${ }^{15}$.

Por último, antes de comenzar, quiero señalar que se notará una descompensación entre la extensión del apartado dedicado a los recursos de naturaleza no retórica en comparación con el dedicado a los recursos de naturaleza retórica. $\mathrm{La}$ causa es simple: los segundos son mucho más numerosos que los primeros, pero, dado que el objetivo del presente trabajo es ofrecer una visión de conjunto, ruego que se disculpe.

\section{Recursos de naturaleza no retórica}

1.1. Los recursos coercitivos, mediante los cuales la divinidad era obligada a cumplir las demandas del mago, se distinguían de otros procedimientos como una cate-

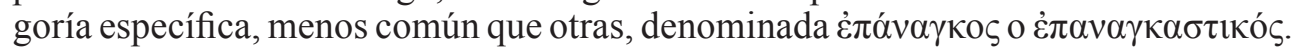
En el diálogo con la divinidad raramente encontramos referencia explícita a la anulación de la voluntad divina, como en el h.Mag. XVII (PGM IV 2242-2417), texto comentado al final de este estudio, en el que el mago le dice a la diosa: $\tau$ ò $\delta \varepsilon i ̃ v \alpha$

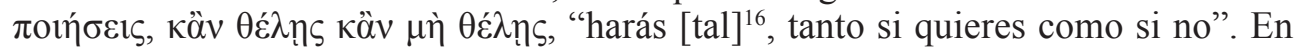
una secuencia de rituales alternativos o en la gradatio de un lógos, los recursos coercitivos aparecen siempre en último lugar, lo que implica que la coerción era considerada el recurso más efectivo, pero también la última opción a la que debía recurrir el mago ${ }^{17}$. El motivo era, probablemente, que la divinidad, obligada en contra de su voluntad, era aún más peligrosa para la integridad del oficiante. Quizás por ello, la mayor parte de los lógoi que encontramos en los papiros mágicos no son coercitivos sino que a los dioses, como al público en el teatro o a un jurado en el tribunal, se los podía convencer. La escasa aparición de este tipo de recursos y su distinción como una categoría aparte ${ }^{18}$, a lo que se puede añadir la prudencia con la que muchos redactores de los papiros mágicos trataban estos procedimientos ${ }^{19}$, son motivos suficientes para argumentar que la coacción no era un rasgo distintivo de la magia.

Los dos recursos fundamentales de carácter coercitivo empleados en el discurso mágico son las fórmulas de conjuro y la amenaza.

15 En consecuencia, quiero advertir que los textos seleccionados no tienen un carácter exhaustivo, sino meramente ejemplar.

16 El texto entre corchetes de la traducción se corresponde con $\delta \varepsilon \tilde{v} v \alpha$, un término empleado por los redactores de los hechizos para referirse a los datos (nombres, peticiones, etc.) a concretar por la persona que empleaba el hechizo, es decir, en un formulario era nuestro equivalente a un campo en blanco.

17 E.g. en $P G M$ II 43ss., tras la descripción de diversas prácticas alternativas para conseguir un oráculo de Apolo, el redactor del papiro refiere en último lugar dos prácticas coactivas, dando incluso una alternativa al procedi-

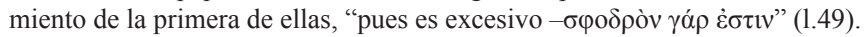

18 Estos son los motivos aducidos por Graf (1991: 194).

19 Vid. supra n.12 y la práctica citada en la n.17. 
(a) Las fórmulas de conjuro, a las que pertenecen los verbos ó $\rho \kappa^{\prime} \zeta \omega^{20}$ y sus compuestos -entre los que destaca, por su frecuencia, $\dot{\varepsilon} \xi o \rho \kappa i \zeta \omega-$ у у $\dot{\varepsilon} \pi ı \kappa \alpha \lambda \dot{\varepsilon} \omega$-en los

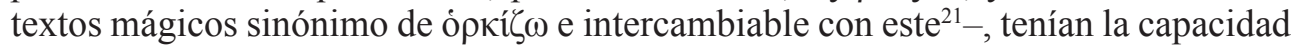
de obligar a las potencias divinas a cumplir la voluntad del mago ${ }^{22}$. Es decir, bastaba pronunciar la fórmula de conjuro junto con el nombre del ser invocado (o exorcizado) -e.g. ó $\rho \kappa i ́ \zeta \omega ~ \sigma \varepsilon, ~ M \alpha \sigma \kappa \varepsilon \lambda \lambda \mathrm{l}$ M $\alpha \sigma \kappa \varepsilon \lambda \lambda \omega^{23}$, "te conjuro, Maskelli Maskello" (PGM III 90)- para que esta entidad apareciera ante el mago arrastrada por el poder de la fórmula. Por ello, este grupo de fórmulas se encuentra a medio camino entre la palabra y el acto, en tanto que son enunciados con un resultado directo sobre la realidad, y como tales pertenecen a la categoría de los "actos de habla" ${ }^{24}$. Su poder performativo enlaza con la creencia, en el ámbito mágico, de que ciertos enunciados, a los que podemos añadir también los nombres divinos ${ }^{25}$ y ciertas palabras "mágicas", como las ephesia grammata ${ }^{26}$, tenían un efecto directo sobre la realidad por acción de un poder intrínseco, que emanaba de la divinidad o de las propiedades fonéticas de la propia palabra. Esta es la principal diferencia entre el "acto de habla" en el contexto mágico y el contexto religioso donde, a excepción del nombre de Dios, la capacidad de un enunciado de convertirse en un "acto de habla" reside en la persona que lo

20 Оркі̧́ grafou, se remonta, lo más temprano, al siglo I a.C., pero se restringe al ámbito dialéctico entre humanos. En la Grecia arcaica y clásica no se hallan testimonios de la imposición de un juramento por un humano a una potencia divina hasta el desarrollo de la creencia de que estas pueden "poseer" a los seres humanos y aún entonces se aplicarán con un sentido muy concreto, el de obligar a la entidad divina a salir del poseso. Sólo en la magia greco-egipcia estas fórmulas se utilizan en la relación entre el hombre y la divinidad en el mismo sentido que lo hacían en la relación entre hombres -a saber, obligar mediante juramento a que alguien haga algo-, vid. Zografou (2015: 268).

21 Zografou (2015: 270), Suárez-Blanco-Chronopoulou (2016: 222-223).

22 Con un amplio abanico de posibilidades que iban desde la simple invocación (hacer que el dios apareciese ante el mago), al exorcismo o acto por el que una entidad divina es obligada a abandonar el cuerpo de un hombre.

23 М $\alpha \sigma \kappa \varepsilon \lambda \lambda_{1}$ M $\alpha \sigma \kappa \varepsilon \lambda \lambda \omega$ es aquí una fórmula mágica; el dios invocado y al que se refiere el pronombre es SethTifón.

24 Zografou (2015: 269 y 276). Por lo que se refiere a los "actos de habla", se trata de enunciados que superan el plano descriptivo de la lengua y poseen, en cambio, un carácter performativo, es decir, su pronunciación equivale o implica una acción, un cambio en el plano extralingüístico. Por la amplia bibliografía existente, me limito a mencionar los estudios de Austin (1970) y Searle-Vanderveken (1985), que asentaron las bases de esta categoría

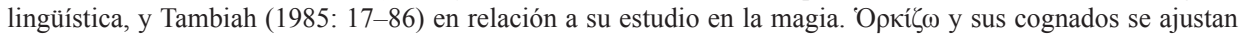
a las características descritas para los enunciados performativos (performative sentences): "These consist of a performative verb used in the first person present tense of the indicative mood. (...) In uttering a performative sentence a speaker performs the illocutionary act named by the performative verb by way of representing himself as performing that act, e.g. I pronounce you husband and wife", vid. Searle-Vanderveken (1985: 2-3).

25 La importancia esencial que tienen los nombres en la magia procede, probablemente, del mundo oriental, donde esta creencia está presente tanto en el mundo semítico como egipcio. En este último se creía que el nombre, Ren, era uno de los componentes del espíritu y en consecuencia parte intrínseca del ser. Quizás el mejor reflejo de esta creencia se encuentre en mitos cosmogónicos donde la divinidad primigenia da lugar a la Creación mediante la imposición de nombres al caos que la rodea, haciendo que este se concrete en las realidades nombradas, vid. Pinch (2002: 61-63). A este mismo tipo de cosmogonía pertenece también el relato del Génesis. Como parte constitutiva del ser, el nombre divino participaba del poder de la potencia nombrada, lo que lo convertía en un poderoso instrumento para quien era capaz de dominarlo, pero al mismo tiempo peligroso. Así el nombre verdadero de Amón causaba la muerte de quien osaba pronunciarlo (P. Leiden I 350, cap.200, v.27). Esta creencia, está también presente en el mundo hebreo, donde a Dios se le llama siempre mediante nombres sustitutivos como Yahvé o Adonai.

26 Fórmula mágica de gran poder formada por seis palabras: $\dot{\alpha} \sigma \kappa \imath \kappa \alpha \tau \alpha \sigma \kappa \imath \alpha 1 \xi \tau \varepsilon \tau \rho \alpha ́ \xi \delta \alpha \mu \nu \alpha \mu \varepsilon v \varepsilon v ́ \varsigma \alpha i ̋ \sigma 1 \alpha$, con variantes, que en origen pudieron haber formado parte de una o varias fórmulas que sí habrían tenido sentido pleno y forma métrica, vid. Bernabé (2003). 
pronuncia, generalmente dotada de una capacidad especial por autoridad divina, y no en la propia palabra ${ }^{27}$.

(b) La amenaza ${ }^{28}$ se asienta sobre un pilar distinto de la mentalidad mágica: la ingenuidad de los dioses. La mayor parte de las amenazas mágicas se basaban en la revelación de secretos sobre la divinidad u ocultación de objetos mistéricos con un significado especial para esta ${ }^{29}$, que no era necesario, realmente, que el mago conociera o poseyese; en el contexto de la magia, las divinidades mágicas no son omniscientes, como ocurre en la religión, sino que, como en el cuento popular, creen a la persona que habla. La efectividad de la amenaza no radicaba, por lo tanto, en la capacidad del mago para cumplirla, sino en la idea de que la divinidad, al escuchar al mago, sin lugar a dudas le creería y obedecería. De hecho, algunas amenazas mágicas se basan en ơ $\delta v ́ v \alpha \tau \alpha$ o "imposibles", que amenazan con trastocar el orden natural y el mundo divino ${ }^{30}$ :

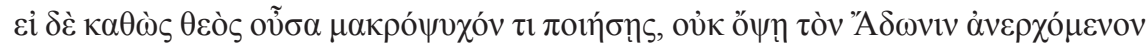

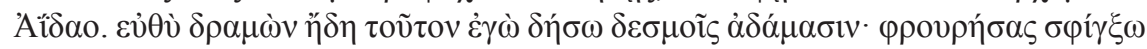

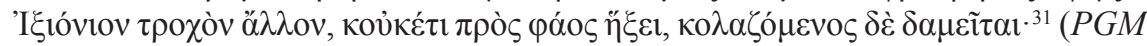
IV 2898ss.)

1.2. Mucho más frecuentes que los recursos coactivos y característicos del discurso mágico son los recursos simpatéticos, que basan su efectividad en la simpatía ${ }^{32}$, una propiedad natural de acuerdo a la cual dos objetos con un vínculo entre sí pueden ejercer influencia uno sobre otro a través de este nexo, lo que les diferencia de los recursos coactivos que funcionan por un poder intrínseco. Esta propiedad, basada en una deducción empírica no científica fruto de la analogía o la casualidad ${ }^{33}$ rigió, por ejemplo, en la medicina hasta el desarrollo del método científico y se encuentra en la base de la magia a nivel universal. El ritual simpatético, por lo tanto, sería aquel en el que la acción ritual, que puede ser de acto o de habla, tiene un efecto sobre la realidad gracias a una analogía; una serie de argumentos del lógos mágico se especializaron en su creación.

27 Un ejemplo claro es Jesucristo, quien, a lo largo del Nuevo Testamento, protagoniza diferentes episodios en los que realiza acciones sólo con pronunciar unas palabras (e.g. la resurrección de Lázaro, vid. Juan 11.43-44). Los Sacramentos, como la Eucaristía, se ejecutan también mediante "actos de habla" pronunciados por los sacerdotes -"esta es la Sangre y el Cuerpo de Cristo"-, igual que en el antiguo ritual eleusino, el sacerdote renovaba anualmente la fertilidad de la tierra mediante la orden "concibe" (vid. Hippol. Haer. 5.7.34.2).

28 Sobre la formulación de este recurso mágico, vid. García Teijeiro (1996: 156). Para su uso en la religión egipcia, vid. Wortmann (1986: 92ss.).

29 E.g. enumeración de distintos actos rituales que, debido al contexto, se deduce que contravienen la ley religiosa

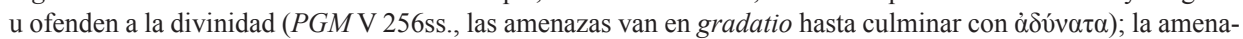
za consiste en la revelación de un nombre secreto que provocará la esterilidad de la tierra ( $P G M$ LXII 8ss.). En $P G M$ IV 2065 y 2248 la amenaza no se encuentra especificada.

30 E.g.: el mago amenaza con impedir la lluvia ( $P G M$ IV 290); un nuevo día (IV 2330); el cielo caerá sobre la tierra, (V 285, cf. III 537); el mago ordenará a otro dios que despedace al que le desobedezca (XII 140ss., similar pero más vaga en LXI 11).

31 Traducción: Si tú, que eres una diosa, actúas con lentitud, no verás a Adonis subir del Hades. Apresurándome, yo lo ataré con cadenas irrompibles; tras tenerlo bajo control, ensamblaré otra rueda ixionia y en modo alguno resucitará, sino que, dominado de esta forma, permanecerá sometido.

32 Algunos autores antiguos la identificaron como el rasgo distintivo de la magia, vid. Plot. 4.4.40ss.

33 La definición de "simpatía ritual" o rito "simpatético" fue establecida en el ámbito de la antropología por S.J. Tambiah, vid. Tambiah (1985: 60-86). Sobre la simpatía en la magia griega y greco-egipcia, vid. Faraone (1991: 8-9). 
(a) Los argumentos similia similibus, reconocibles por el empleo de la correlación comparativa $\check{\sigma} \sigma(\pi \varepsilon \rho)$... oũ $\tau \omega \varsigma . .{ }^{34}$, crean un nexo, establecido por la fórmula, entre algo que el practicante de magia tiene y sobre lo que actúa físicamente, y la realidad o la persona a la que el hechizo va dirigido. Así, la acción realizada por el practicante mágico sobre dicho objeto repercute directamente sobre el objetivo escogido. Es decir, estamos ante una estrategia de carácter performativo ${ }^{35}$ que, no obstante, se diferencia del "acto de habla" en que el enunciado en este caso sí va acompañado de una acción extra-lingüística, descrita en la cláusula de $̋ \sigma(\pi \varepsilon \rho)$; el acto perlocutivo radica, entonces, en la cláusula de oṽ $\omega \varsigma$, por acción de la cual el acto realizado por el practicante de magia se extiende más allá de su realidad extra-lingüistica inmediata y alcanza a la

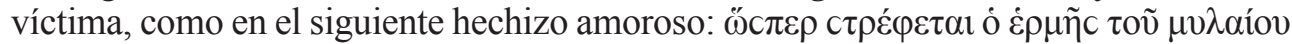

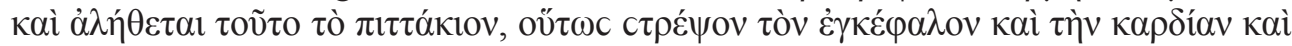

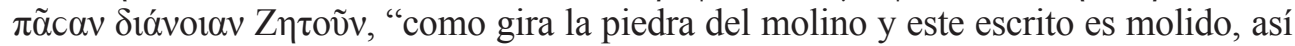
cambie la mente, el corazón y todo pensamiento de Zeto" (SM 56, 1-6ss. $)^{36}$.

Faraone ha señalado que, debido a la importancia que tiene en los argumentos similia similibus el empleo de los nexos comparativos y la pervivencia formular de los mismos sin apenas cambios, la eficacia de estos procedimientos parece asentarse sobre una firme creencia en el poder del lenguaje $\mathrm{e}^{37}$.

(b) La historiola es un recurso de gran antigüedad y complejidad que nace de la combinación de la narración de la actuación de una potencia divina, como referente, y el principio de simpatía, por el que la narración, que adquiere un poder performativo mediante su pronunciación, actúa sobre la realidad por analogía entre el tiempo mítico y la dimensión humana. En cuanto a cómo sucede esto, los estudios actuales se decantan por la teoría de M. Eliade, según la cual el poder de la historiola es intrínseco al acto narrativo: el propio acto de la narración, con independencia de la naturaleza del acto narrado, es el que provoca que lo que sucede en el plano mítico tenga una reacción semejante en una situación presente de carácter análogo ${ }^{38}$. La propiedad enunciada por Eliade, que ha sido denominada "narrative power" o "mythical referentiality" ${ }^{39}$, puede verse en el siguiente hechizo contra la fiebre $(P G M \mathrm{XX})^{40}$ :

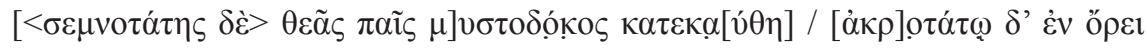

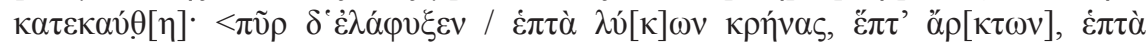

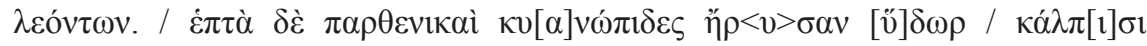

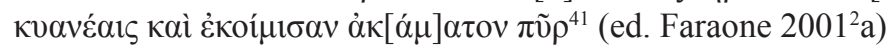

34 García Teijeiro (1996: 155ss.) recoge una lista completa de pasajes en los que se emplea este recurso, con especial atención a las fórmulas comparativas empleadas.

35 Sigo en esta categorización a Kropp (2010: 396, 371-372), quien considera los argumentos similia similibus un subtipo de fórmula performativa, igual que lo serían los "actos de habla". Por el contrario, Faraone distingue ambos como categorías diferentes (Faraone 1991: 3-10).

36 Este ejemplo procede de un testimonio de magia aplicada, pero puede encontrarse el mismo recurso, basado en la idea del amor como fuego que quema en $P G M$ IV 1540-41, que es un formulario. La utilización de este recurso en la magia amorosa está ya atestiguada en época helenística en el Idilio II de Teócrito, vv.28-29.

37 vid. Faraone (1991: 8-9).

38 vid. Eliade (1963).

39 vid. Frankfurter $\left(2001^{2}\right)$, Versnel (2002).

40 Este papiro, uno de los de contenido mágico más antiguos conservado, contiene tres breves encantamientos poéticos de carácter iatromágico. Sobre el mismo vid. Maas (1942), Daniel (1988), Faraone (1995).

${ }_{41}$ Traducción: [El hijo de la más augusta diosa], el iniciado fue quemado. En la más alta montaña él fue quemado. $<$ El fuego devoró> siete fuentes de lobos, siete de osos, siete de leones. Siete doncellas de ojos oscuros sacaron agua con cántaros oscuros y apagaron el inextinguible fuego. 
La acción de las siete doncellas que apagan el fuego que abrasa al hijo de la diosa actúa, por el poder performativo de la narración y gracias a la analogía, sobre un enfermo febril, cuya fiebre, se suponía, se extinguía igual que el fuego del relato. Así, a diferencia del argumento similia similibus, la historiola no necesita establecer una comparación para que se produzca la analogía, comportándose estos dos recursos en el acto ritual como la metáfora y la comparación en el plano retórico.

Los ejemplos que nos han transmitido los textos mágicos apoyan la teoría de Eliade al mostrar que estas narraciones no se asientan sobre la popularidad de un acontecimiento mítico, siendo en su mayoría acciones desconocidas, como la del ejemplo citado, $\mathrm{y}$, aunque en su mayoría son míticas (protagonizadas por personajes divinos), no tenían necesariamente porqué serlo, como en el siguiente hechizo latino para detener una hemorragia: Stulta femina super fonte sedebat et stultum infantem in sinu tenebat. Siccant montes, siccant valles, siccant venae vel quae de sanguine sunt plenae, "una mujer necia sobre la fuente se sentaba y un niño necio sobre su regazo sujetaba. Se secan los montes, se secan los valles, se secan las venas que de sangre están llenas" (Heim, 1892: 111).

\section{Recursos de naturaleza retórica}

Las semejanzas entre el discurso poético, con la propiedad de mover las emociones (indignarnos, hacernos reír, entristecernos...), y el discurso mágico, que se creía capaz de subyugar y hechizar la voluntad de hombres y dioses, llamó ya la atención en la Antigüedad. El famoso sofista Gorgias, en el Encomio de Helena (Gorg. fr. 11 Diels-Kranz), describe la palabra mágica de la siguiente forma:

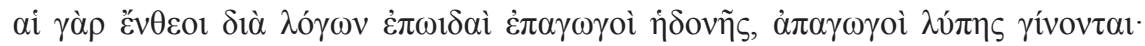

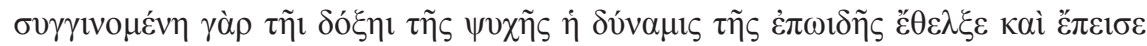

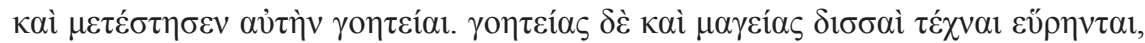

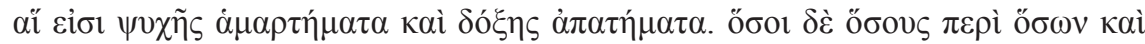

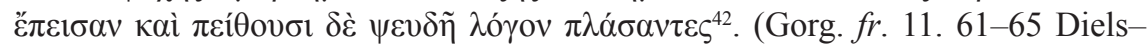
Kranz).

En esta pieza epidíctica, de mención obligada cuando se habla sobre magia, poesía y retórica ${ }^{43}$, el de Leontinos quiso demostrar que un discurso persuasivo, para ser eficaz, necesitaba argumentos basados en estrategias racionales y un lenguaje seductor basado en estrategias poéticas. Los estudios sobre el discurso y la lengua de la magia han demostrado que Gorgias no se equivocaba al señalar la magia como un ámbito en el que se explotó al máximo la capacidad de la palabra tanto para dar forma a argumentos persuasivos como para mover la parte irracional del alma. Como muestra, realizaré un elenco de los recursos retóricos del discurso mágico partiendo del nivel fonético, pasando por el nivel léxico-gramatical, hasta llegar a la construcción argumental.

42 Traducción: Los encantamientos, inspirados mediante las palabras, producen placer y apartan el dolor. La fuerza de la fascinación, adueñándose de la opinión del alma, la domina, la convence y la transforma como por magia. Dos artes de la $\gamma$ ¡ $\tau \varepsilon i ́ \alpha$ y la $\mu \alpha \gamma \varepsilon i ́ \alpha$ han sido creadas, las cuales inducen errores del alma y engaños de la opinión. ¡Cuántos a cuántos han engañado y engañan tras dar forma a un razonamiento falso sobre cuántas cosas!

43 Vid. Romilly (1975:1-27), Levi (1975), García Teijeiro (1987:143-144), Fournier (2013). 
2.1. La palabra mágica, como la poética, llamaba la atención sobre sí misma a través de su sonoridad; tenía una cadencia especial, caracterizada por la abundancia de repeticiones, la aliteración y la atracción por los grupos de fonética anormal (de acuerdo a los parámetros griegos o latinos), que distinguía los enunciados mágicos del habla normal ${ }^{44}$. Para conseguirlo, en el discurso mágico abundan los recursos del lenguaje y las figuras de dicción, sobre todo basados en la repetición por iteración de una misma estructura (fonemas, palabras, sintagmas u oraciones enteras) en esquemas bimembres, trimembres o plurimembres, motivo por el que es posible encontrar recursos repetitivos a todos los niveles del discurso, desde el fonético a la macroestructura del texto e incluso en la macroestructura de la praxis, pudiendo un lógos mágico consistir en la repetición de un mismo esquema durante un número indeterminado de veces ${ }^{45}$.

(a) A un nivel rítmico, un cierto número de fórmulas y hechizos emplean formas poéticas como el trímetro yámbico y el hexámetro ${ }^{46}$. Estas, a pesar de su posibilidad de variación, poseen una naturaleza repetitiva cuyo empleo en el discurso mágico, como E. Szepes señaló ${ }^{47}$, va más allá de una finalidad artística: sus compositores no buscaban crear un poema hermoso, sino reforzar el poder "mágico" del lógos mediante el empleo de una forma -la poética- que a nivel fonético establecía una pauta rítmica de carácter iterativo en las palabras del hechizo ${ }^{48}$. Este recurso se sumaba a otros de naturaleza argumental, pero también de naturaleza fonética, estructural, etc.

(b) A un nivel fonético, la repetición de ciertos grupos de sonidos crea aliteraciones que, lejos de ser accidentales, fueron un recurso intensamente buscado en la lengua de la magia. Es característico especialmente de las invocaciones y fór-

44 M. García Teijeiro, uno de los filólogos que más a fondo se ha dedicado al estudio de los fenómenos sintácticos y fonéticos de la legua de la magia, concluye que la importancia del elemento fonético es tal que la pronunciación de la palabra parece haber sido lo esencial, siendo su notación escrita un fenómeno secundario, vid. García Teijeiro (1989: 237). Se refiere aquí, no obstante, a la notación escrita de la palabra que debía ser pronunciada y que no hay que confundir con la notación de aquellas palabras o símbolos que no se pronunciaban, pero que eran igualmente importantes para la ejecución del rito mágico, y que son a los que hace referencia Graf cuando

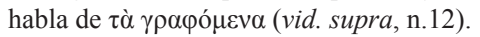

45 Por ejemplo, véase PGM XVI, una lámina de plomo catalogada como P. Louvre 3378 (siglo I d. C.). A pesar de su extensión (unas 74 líneas), la defixio en realidad consiste en la reiteración de un único texto de maldición (una matriz de aproximadamente cinco líneas), que se llega a repetir 9 veces con mínimas variantes, vid. Jordan (1988).

46 Estas no son las dos únicas formas métricas empleadas en las fórmulas y hechizos mágicos, pero sí las dos más abundantes y, probablemente, más antiguas, ya que Faraone (1995), (2009), (2011), en sus estudios sobre fórmulas mágicas (hechizos breves compuestos por uno o dos versos), ha detectado en ellos rasgos de origen oral que confirman como acertada la intuición de García Teijeiro (vid. supra, n. 43) sobre el carácter secundario de la notación escrita de la palabra mágica. La extensión de estos puede variar entre uno o tres versos (fórmula) a largos poemas (hasta 103 versos en el caso de h.Mag. XVII). Estos últimos se encuentran recogidos en Preisendanz (19742: 237-266), reciben, por convención, el nombre genérico de 'himnos mágicos' (abreviados aquí como h.Mag.), pero sobre algunos permanece la duda sobre si fueron compuestos por los redactores de los papiros mágicos o, al contrario, tomados de la literatura religiosa y oracular contemporánea.

47 E. Szepes (1976: 210-211) ha sido el primero en señalar el empleo de la versificación en el discurso mágico como un recurso "mágico" y no artístico-literario.

48 En el verso greco-latino, que era de naturaleza rítmica, no acentual, el ritmo se conseguía mediante la alternancia, de acuerdo a diferentes secuencias dependiendo del verso empleado, de sílabas breves y largas. En relación con este discurso puede señalarse también que, quizás por ello, en el empleo de la versificación hexamétrica en los himnos mágicos (cf. supra, n.46) se nota una marcada tendencia al empleo de versos de naturaleza holodactílica. 
mulas mágicas, en las que se obtenía por varios procedimientos de naturaleza re-

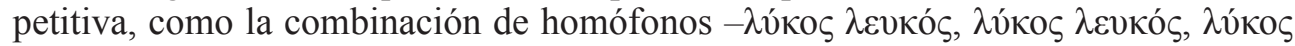
$\lambda \varepsilon v \kappa o ́ s ~[l i ́ k o s ~ l i k o ́ s]{ }^{49}$ (SM 34, col.c, 1-4)-, la variación mediante la formación de

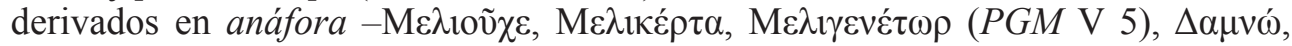

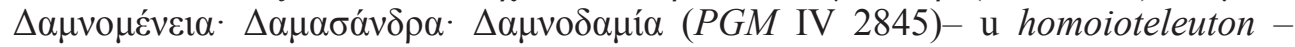
$\beta 1 \alpha ́ \sigma \alpha v \delta \rho \alpha, \delta \alpha \mu \alpha ́ \sigma \alpha v \delta \rho \alpha, \kappa \alpha \lambda \varepsilon ́ \sigma \alpha v \delta \rho \alpha, \kappa \alpha \tau \alpha v i ́ \kappa \alpha v \delta \rho \alpha$ (PGM VII 696). Este tipo de procedimientos se encuentran también en la formación de palabras "mágicas" como los palíndromos $(\alpha \beta \lambda \alpha v \alpha \theta \alpha v \alpha \lambda \beta \alpha)^{51}$ y las ó $\sigma \eta \mu \alpha$ óvó $\mu \alpha \tau \alpha(\alpha \kappa \rho \alpha \mu \mu \alpha \chi \alpha \mu \alpha \rho 1)^{52}$, cuya sonoridad era la base de su poder mágico y cuya composición podía hacerse por

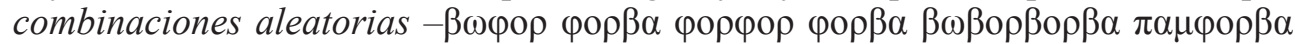
$\varphi \omega \rho \varphi \omega \rho$ (PGM IV 1256ss)- o gradaciones crecientes o decrecientes sobre una raíz ${ }^{53}$. Al estudiarlos, García Teijeiro ha incidido en el gusto de la lengua de la magia por las estructuras fónicas anormales, rasgo también presente en otras manifestaciones especiales del lenguaje como los gritos orgiásticos y las voces extáticas, fenómenos que según García Teijeiro podrían haber influido en la fonética de las palabras mágicas al considerarse de naturaleza divina y distinguir estos enunciados del habla cotidiana $^{54}$.

(c) A nivel léxico, la forma más simple de iteración es la repetición de una

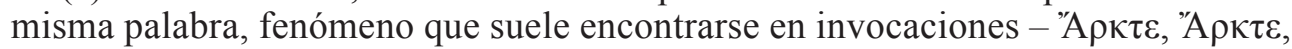

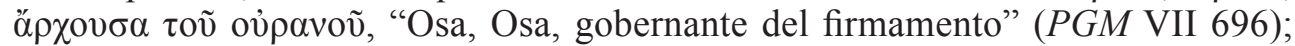
$\chi \alpha \tilde{\imath} \rho \varepsilon, " H \lambda \imath \varepsilon, \chi \alpha \tilde{\imath} \rho \varepsilon, " H \lambda \imath \varepsilon, \chi \alpha i \tilde{\rho} \varepsilon$, , "Salve, Helio, salve, Helio, salve" (PGM XXIIa 18); $\lambda \tilde{v} \varepsilon, \lambda \tilde{v} \varepsilon \pi$ óvovs, $\lambda \tilde{v} \varepsilon$, "libera, libera el dolor, libera" (SM 32.12) - y otros sin-

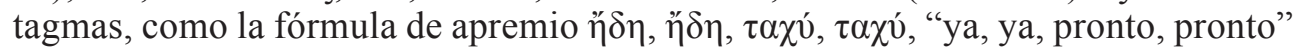
(PGM I 62, III 36, 85, 124, IV 1919, etc.). La reduplicación servía para intensificar la urgencia de la llamada y reforzar el carácter imperativo del verbo. Se trata de un tipo de geminación expresiva también presente en plegarias de carácter popular, no literario ${ }^{55}$, cuyo efecto podía incrementarse mediante acumulación (e.g. ő $\rho \tau \imath$

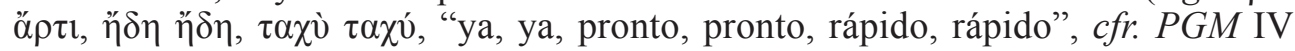
973, 1593).

49 Este amuleto se data en el siglo VI, momento en el que, debido a la acción del iotacismo sobre el vocalismo griego, $v$ y el diptongo $\varepsilon v$ se pronunciaban ambos [i], vid. Gignac (1976: 228-230).

50 Además de las aquí mencionadas, García Teijeiro (1989: 238ss.) señala otras manifestaciones de fonética llamativa que aparecen en los textos mágicos como los nomina barbara y las voces naturales.

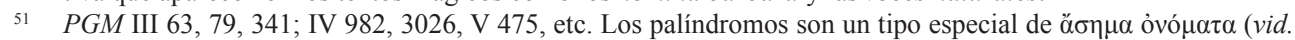
infra) compuesto por palabras que se leen igual de derecha a izquierda que de izquierda a derecha, sobre las que se podía jugar por ampliación, mediante la reduplicación de los componentes centrales: $\alpha \beta \lambda \alpha v \alpha \theta \alpha \lambda \alpha \alpha \beta \lambda \alpha$ (PGM LXXI 4), $\alpha \beta \lambda \alpha v \alpha \theta \alpha v \alpha \theta \alpha v \alpha \beta \lambda \alpha$ (PGM XVIIc 1).

52 Palabras propias de la lengua mágica que carecían de significado pero que, se pensaba, tenían un poder especial. Podían emplearse como fórmulas o como nombres "mágicos" de la divinidad.

53 Esta técnica de composición es denominada en los papiros mágicos $\pi \tau \varepsilon \rho v ́ \gamma$ iov, literalmente "en forma de ala" (vid. $L M P G$ ), ya que la secuencia, en la que se iban quitando, o al revés, añadiendo letras a una forma matriz, solía escribirse en sentido piramidal, e.g. $\alpha \kappa \rho \alpha \kappa \alpha v \alpha \rho \beta \alpha \cdot \kappa \alpha v \alpha \rho \beta \alpha \cdot \alpha v \alpha \rho \beta \alpha \cdot v \alpha \rho \beta \alpha \cdot \alpha \rho \beta \alpha \cdot \rho \beta \alpha \cdot \beta \alpha \cdot \alpha(P G M$ II 1), combinando el poder fonético con la disposición gráfica.

54 García Teijeiro (1992).

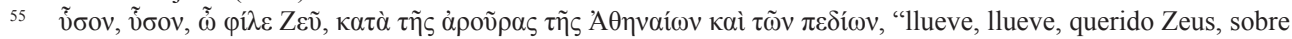

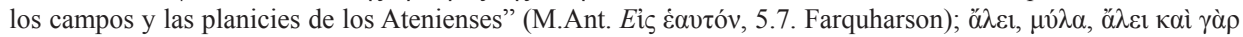

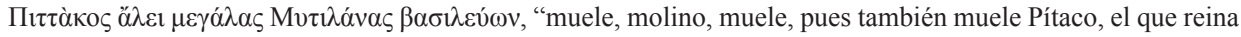
sobre la gran Mitilene" (Plu. 157e). Esta última es canción de trabajo, que, no obstante, tiene ecos en hechizos mágicos, vid. Zografou (2016: 161-164). La geminación expresiva se nota también en la formación de los nom-

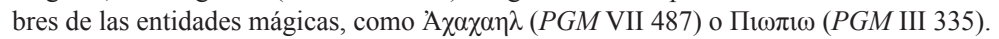


Una figura de repetición intensiva muy utilizada también fue la políptoton, que repite palabras formadas sobre la misma raíz como en la fórmula de petición $\tau \dot{\imath} \lambda \varepsilon 1$ $\tau \varepsilon \lambda \varepsilon i ́ \alpha v \tau \varepsilon \lambda \varepsilon \tau \eta ́$ v, "lleva a término este rito perfecto" (PGM XII 306) ${ }^{56}$, creando además un efecto aliterativo. Esta figura de repetición fue especialmente utilizada en los hechizos eróticos para expresar el acto sexual y el deseo erótico bajo esquemas similares al del siguiente ejemplo ${ }^{57}$ :

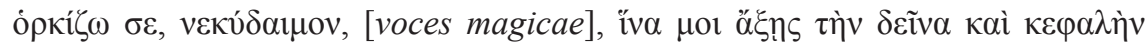

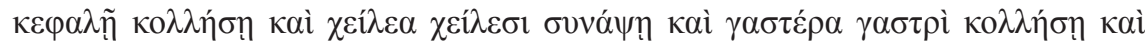

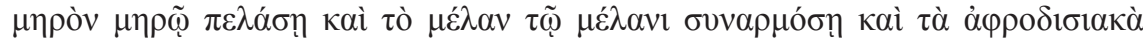

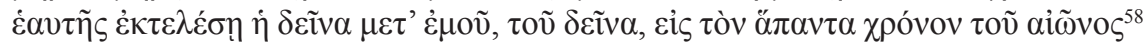
(PGM IV 400ss.)

En el discurso mágico, el efecto de la políptoton se combinó con el de otras figu-

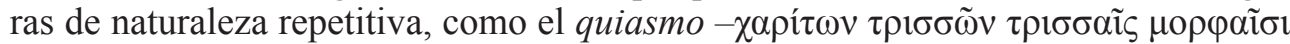
( $P G M$ IV 2791)- y, como se ha visto en el caso de la repetición simple, podía inten-

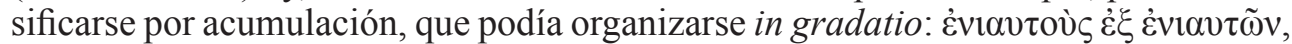

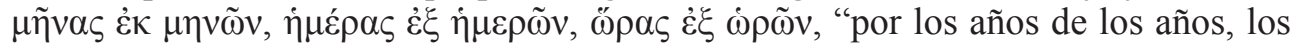
meses de los meses, los días de los días, las horas de las horas" (PGM IV 343). Fue especialmente usado también en forma de genitivo de encarecimiento: $\theta \varepsilon \dot{\varepsilon} \theta \varepsilon \tilde{\omega} v$,

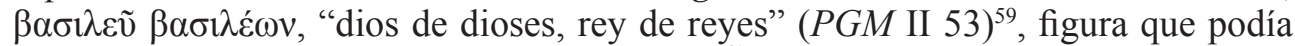

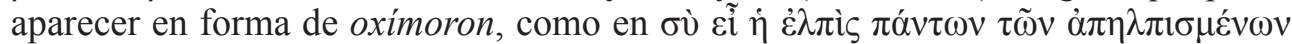

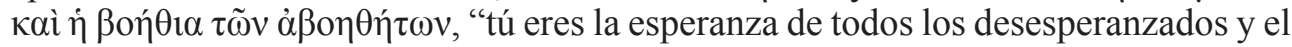
socorro de todos los que no tienen ayuda" (PGM P 20 ver. 34ss.), donde la contraposición contrasta, además, con la paronomasia, difícil de recoger en una traducción.

(d) Superando el nivel de la palabra, la repetición se establece con frecuencia también entre cláusulas y sintagmas por medio de diversas figuras como la anadi-

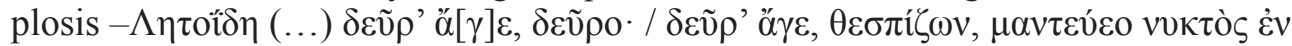
๓̋p ${ }^{60}$, "Letoida, aquí, ven aquí, aquí ven, dando vaticinios, profetiza en este momento de la noche" (rítmicamente reforzada por el empleo del metro hexámetro)-,

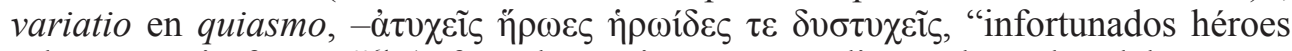
y heroínas sin fortuna" ${ }^{61}$ (reforzada rítmicamente mediante el empleo del trímetro yámbico)-, el paralelismo y la anáfora, estructuras que pueden combinarse y repetirse durante largos periodos como en el siguiente ejemplo:

56 Se trata de una variante de una fórmula que debió gozar de gran difusión, como atestiguan los varios ejemplos transmitidos en PGM y SM; fue, incluso, parodiada por Aristófanes (Ael. N.A. $12.9=$ Ar. Amphiaraus fr. 29 Kassel-Austin), vid. Faraone (2011:197-98).

57 E. Suárez, que se ha encargado del estudio de esta figura en la magia erótica, ha sugerido que esta clase de repetición intensiva, en este tipo de magia, pudo tomarse prestada de la poesía helenística y contemporánea, de la que recoge distintos ejemplos, donde era un recurso muy empleado por su eficiente expresividad, vid. Suárez (2014a).

58 Traducción: Te conjuro, demon de un muerto, para que traigas junto a mí a [nombre de la víctima], unas cabeza con cabeza, ates labios con labios y unas vientre con vientre y acerques muslo con muslo y juntes lo negro con lo negro y [nombre de la víctima] lleve a término sus deseos conmigo, [nombre del defigens], por todo el tiempo de la eternidad.

59 Más ejemplos en García Teijeiro (1996: 159ss.). Esta figura, aunque también se atestigua en el mundo griego, es especialmente característico del lenguaje bíblico.

60 h.Mag. 10. 2-3 = PGM VI 26-27

61 h.Mag. $25.18=P G M$ IV 1421 


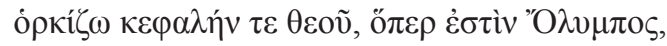

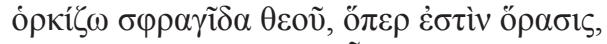

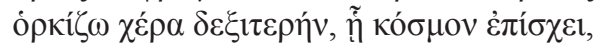

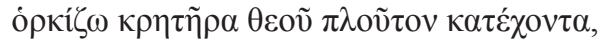

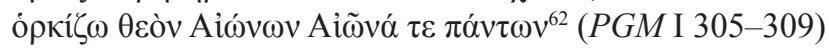

La necesidad de la lengua de la magia en insistir en lo que se desea y referirlo siempre por entero tiene como consecuencia la repetición de cláusulas con un propósito enfático ${ }^{63}$, como en el hechizo hexamétrico de PGM IV 2242-2417 (h.Mag.17)

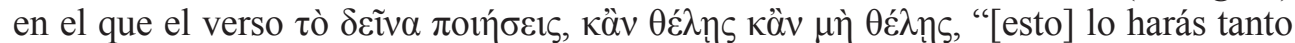
si quieres como si no" ${ }^{64}$ se repite cuatro veces a lo largo del hechizo. Este rasgo estilístico, que se atestigua ya en textos mágicos tan tempranos como la Gran Defixio de

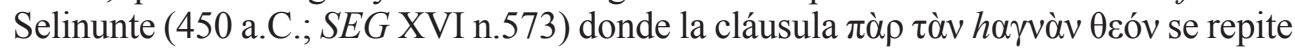
ocho veces en dieciséis líneas, fue percibido como un estribillo y a través de tal recurso poetas como Teócrito o Virgilio intentaron emular la cadencia de los hechizos ${ }^{65}$.

Con un carácter general, puede notarse además en todos los ejemplos citados una tendencia a la superposición de estos recursos, que se acumulaban hipercaracterizando estilística y fonéticamente el discurso mágico en busca de un efecto de salmodia mediante el cual "hechizar" a las divinidades o personas implicadas. Esta es la diferencia fundamental entre el empleo de estas figuras en la magia y en la literatura: la finalidad, pues, a pesar de que todos los recursos aquí enumerados son propios del lenguaje poético, en el discurso mágico no se empleaban para embellecer el texto (intención artística). Las letras y sus sonidos son elementos nucleares del ritual mágico ${ }^{66}$ y su repetición provocaba efectos acústicos que en la magia se consideraron un medio eficaz para lograr cautivar a los dioses ${ }^{67}$; este uso del lenguaje, que en la literatura buscó generar una sensación de placer o una moción del pathos, en la magia se empleó para dominar a los dioses o la realidad (e.g. el cuerpo humano, en la magia médica).

No obstante, el repetitivo estilo de la lengua de la magia tiene también otras causas intrínsecas al ritual mágico, como la necesidad de hablar con gran claridad y precisión para evitar malentendidos con los dioses que derivasen en la ineficacia del ritual, aspectos que entrañan una repetitividad y redundancia que no es exclusiva del discurso mágico, sino que puede encontrarse también en la lengua judicial y legal ${ }^{68}$ o en distintas formas de literatura popular ${ }^{69}$, por lo que están presentes en las inscripciones de vasos y tumbas, así como en himnos no literarios.

2.2. El segundo grupo de recursos de naturaleza retórica empleado en el discurso mágico es el que atañe a la elaboración de argumentos que buscan justificar la petición de la persona que realiza el hechizo o rito.

62 Traducción: Conjuro la cabeza del dios, que es el cielo,/ conjuro el sello del dios, que es la visión,/ conjuro la mano derecha con la que sostiene el cosmos,/ conjuro la crátera del dios que contiene riqueza,/ conjuro al dios de Eones y al Eón entre todos.

63 Sobre este recurso y otros ejemplos, vid. García Teijeiro (1989: 237).

64 Sobre este texto, vid. infra, §.3.

65 Vid. Theoc. Id. II o Virg. Ecgl. VIII.

66 Vid. Dornseiff (1998), Waegeman (1987).

${ }^{67}$ Garcia Teijeiro (1996: 163)

68 Levi (1975).

69 Vid. García Teijeiro (1987: 144-146); (1989); (1996: 262-3). 
(a) Los argumentos basados en la moción del pathos son un conjunto de recursos con relación a los cuales la magia tuvo su modelo en la oratoria.

Así es, al menos, en el caso de la diabolé ${ }^{70}$, recurso retórico que en la oratoria consistió en la creación de una distancia emocional entre el tribunal y el oponente/ acusado y que en la magia se empleó en la magia agresiva ${ }^{71}$ para generar en el dios cierta antipatía hacia la persona contra la que iba dirigido el hechizo, retratándola de tal manera que atrajera sobre sí la hostilidad de la divinidad e incluso su ira. Dado que se enclavaba en un contexto de comunicación con lo divino, la diabolé mágica se especializó en la calumnia de carácter religioso o ritual, atribuyendo a la víctima diversos crímenes de naturaleza religiosa (difamación de mysteria, destrucción de imágenes sagradas, blasfemia, ritos contra lege) con los que el defigens, la persona en cuyo nombre se realizaba el ritual, se aseguraba de privar a la víctima del favor divino $^{72}$. Para lograrlo, el defigens ponía especial cuidado en marcarla como $\mu \alpha \iota \rho ́ s$,

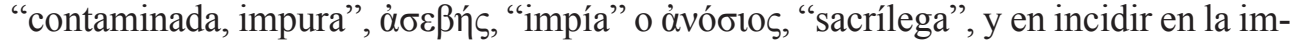
piedad de los crímenes cometidos para magnificarlos, como en el siguiente ejemplo:

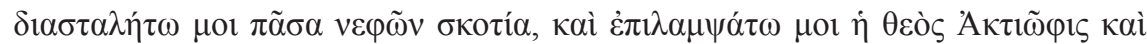

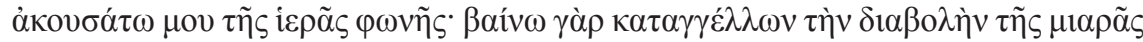

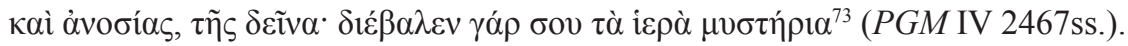

Para justificar la petición del defigens, el efecto de la diabolé podía incrementarse mediante la combinación con su opuesto: la compasión o creación de un lazo emocional entre la divinidad y la persona que hacía la petición, efecto que en la magia se buscó, por ejemplo, resaltando la naturaleza piadosa del defigens. Ambos quedan bien ilustrado en PGM LI 24-25, una defixio en la que el defigens, Nilamón, se presenta como öбı૬, "devoto, religioso", lo que aumenta el delito de la víctima, su propio hijo,

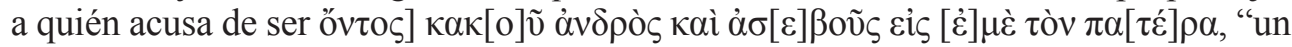
hombre malvado y sacrílego hacia mí, su padre" (11.19-20). En otros casos, como este hechizo dirigido a las almas de los muertos, la moción de la compasión, de nuevo combinada con la diabolé, se asienta en motivos meramente patéticos:

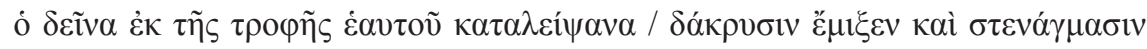

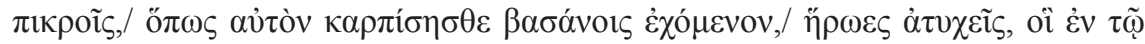

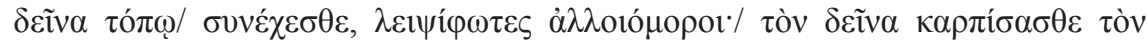

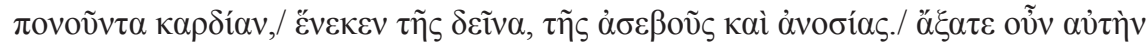
$\beta \alpha \sigma \alpha v i \zeta o \mu \varepsilon ́ v \eta v^{74}$ (h.Mag. 25.6-13 = PGM IV 1410ss.)

70 Sobre la diabolé en la oratoria, vid. Carey (2004); para la diabolé en la magia, vid. Eitrem (1924), Herrero Valdés (2011), Blanco (2013a) y Blanco-Chronopoulou (2018).

71 Como se verá a continuación, este recurso es propio de la magia agresiva porque requiere la existencia de un "oponente" contra el que dirigirlo (lo que en la magia se llama "víctima"); por ello, no hubiera tenido razón de ser en la magia médica o en la magia adivinatoria donde este oponente no existe.

72 Un estudio de este tipo de recurso mágico en Blanco-Chronopoulou (2018).

73 Traducción: Que se disperse toda oscuridad de las nubes y brille para mí la diosa Actiofi y escuche mi sagrada voz, pues voy a referir la calumnia de la impura y sacrílega, de [nombre de la víctima]. Pues ella ha difamado sus sagrados misterios.

74 Traducción: [Nombre del defigens] ha mezclado unas migajas de su propio alimento con sus lágrimas y con gemidos amargos para que a él, que está dominado por el sufrimiento, le deis disfrute, héroes desdichados que en este lugar yacéis juntos tras haber dejado la luz por distintos motivos. Conceded disfrute a este que sufre en su corazón por causa de [nombre de la víctima], la impía y sacrílega. Traedla, así pues, sometida a tormentos. 
La compasión, que en términos aristotélicos puede definirse como la capacidad para compadecerse por los que sufren un mal sin merecerlo ${ }^{75}$, fue brillantemente explotada por grandes oradores de la Antigüedad en ilustres ejemplos como Sobre la muerte de Eratóstenes de Lisias o el Pro Quinctio ${ }^{76}$ de Cicerón, ejemplos donde se ve una cuidada selección del lenguaje y un amplio uso de la adjetivación ${ }^{77}$ similares a los del ejemplo presentado.

(b) Otros recursos persuasivos se especializaron en los argumentos de autori$d a d$, argumentos que se asentaban en una presentación "prestigiosa" del practicante de magia ante los dioses a través de la cual este argüía una autoridad legítima para solicitar su obediencia.

Una de las formas más difundidas fue la asunción por parte del mago de una identidad ficticia en su discurso mediante la identificación con un ser o personaje que intimidase al dios invocado. Este recurso es fácilmente reconocible por el empleo de

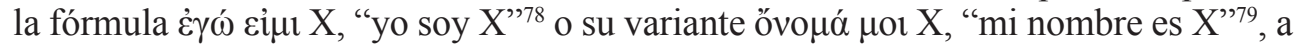
través de las que el oficiante se presenta ${ }^{80}$. Su carácter argumental queda patente por el frecuente empleo de estas fórmulas en oraciones subordinadas de carácter causal ${ }^{81}$. La identificación no tenía porqué asentarse sobre el nombre de un dios conocido; el mago podía identificarse con personajes de autoridad reconocida en la tradición mágica, como Moisés (PGM V 110ss. $)^{82}$, pero también con potencias mágicas de

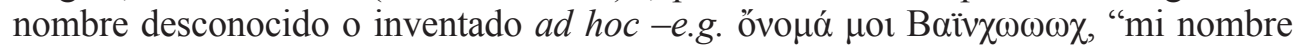

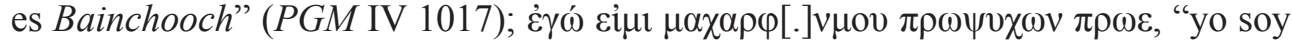
macharf[.]nmou propsuchon proe" (IV 536). El origen de este recurso, en especial de

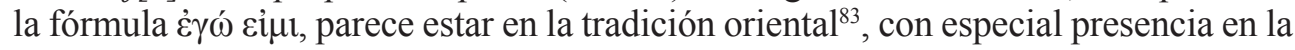
tradición egipcia donde ya se empleaba en la aretalogía isíaca, una forma hímnica a través de la que el sacerdote enunciaba las obras de Isis en primera persona mediante la fórmula "yo soy". En la tradición mágica habría evolucionado de un estilema hímnico a una asunción "real" de la identidad de la potencia divina por parte del oficiante,

\footnotetext{
75 Sobre el concepto aristotélico de compasión, vid. Arist. Rh. II. 8.

$76 \quad$ Vid. especialmente Cic. Quinct. 97.

77 Sobre el uso y el abuso del lenguaje en la literatura para la caracterización de los personajes, vid. Passeti (2015).

78 Sobre esta fórmula y su tradición literaria, vid. Norden (1913:186-201), Schweizer (1939), Bergman (1968), Thyen (1996), Chiarini (2016).

79 Ambas son, de hecho, equivalentes según Chiarini (2016: 96).

80 Este recurso es especialmente llamativo en PGM XII, donde se recoge un lógos que contiene un larguísimo argumen-

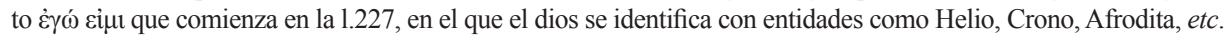

81 Esta afirmación se asienta sobre datos cuantificables, como demuestra Rodríguez Merino, quien, en su estudio

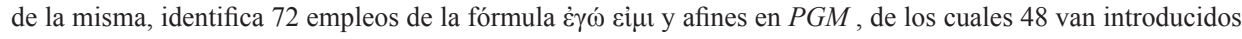

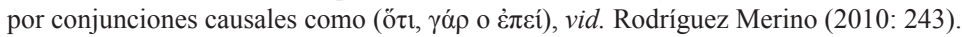

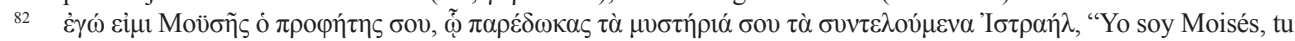
Profeta, al que entregaste tus misterios que son celebrados por (el pueblo) de Israel”. Entorno a la figura de Moisés, por su autoridad en la tradición hebrea y bíblica y sus poderes de origen divino, surgió una tradición místico-mágica de carácter autoritativo que lo veía como un mago, similar a la que se genera en torno a otros personajes como Salomón u Orfeo, y que emplea su nombre en hechizos como el citado para reforzar su poder o garantizar su eficacia, atribuyéndosele por este principio varios pseudoepígrafos (PGM VII 619-27; XIII 1-343 y 343-646; XIII 971-973). Sobre Moisés y su recepción en la magia, vid. Gager (1972: 134-161) y (1994); sobre el fenómeno de la pseudoepigrafía en la magia vid. Suárez (2014b, con especial atención a pp. 255-56 sobre Moisés).

83 Además de en el mundo egipcio, esta fórmula tiene también presencia en el Antiguo y Nuevo Testamento. En estos, la fórmula se pone en boca de la propia divinidad, que se presenta ante alguien; su finalidad es instructiva, puesto que, más allá del personaje al que están dirigidos en el contexto literario, estas aretalogías están dirigidas a toda la comunidad de creyentes para los que fue escrito el Testamento.
} 
llegándose, en algunos textos, a una indistinción entre la potencia invocada y el oficiante $^{84}$, como si, a través de esta fórmula, el mago pudiera incluso asumir la identidad de esta potencia, convirtiendo la voluntad del dios en la suya propia.

Una variante de la anterior es la autoatribución de acciones míticas en beneficio del dios invocado, como en PGM IV 180ss. donde el mago se presenta como $\sigma 0 ́ \mu \mu \alpha \chi 0 \varsigma$ del dios Seth-Tifón con el objetivo de ganarse su favor:

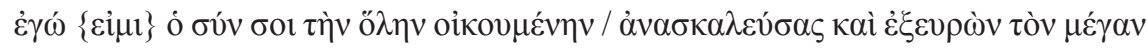

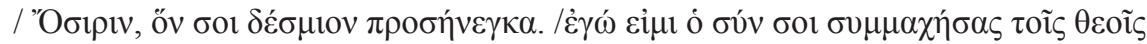

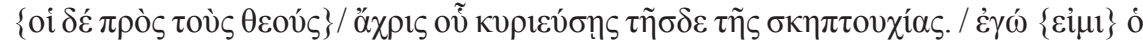

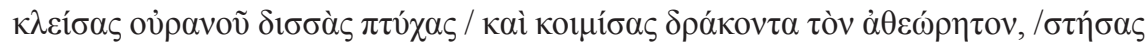

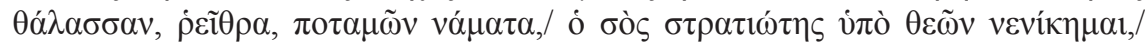

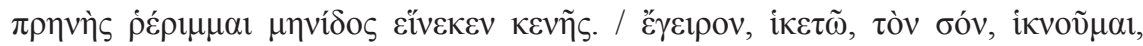

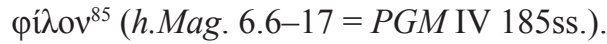

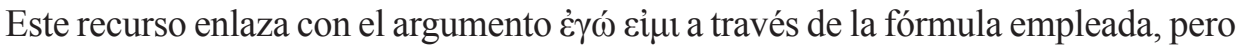
no en la función, ya que la asunción de la identidad divina no se realiza con un carácter autoritario sino meramente autojustificativo, apelando a la moción del pathos al identificar al practicante de magia con un personaje mítico "aliado" del dios.

Una tercera variante de la presentación prestigiosa, similar a la anterior, es en la que el mago se presenta ante el dios como un seguidor de su culto, bien un "iniciado

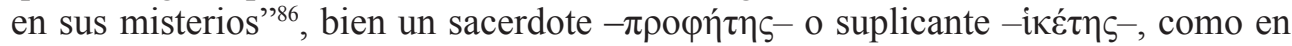
$P G M$ VI+II ${ }^{87}$ 6-20, un himno hexamétrico en el que el mago dice al dios presentar-

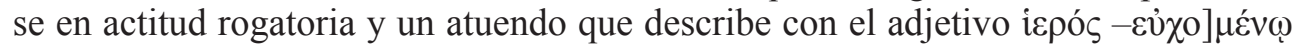

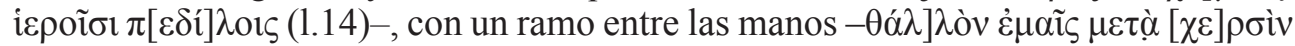
Ě $\chi 0 v \tau \imath ~(1.15)-$, lo que sabemos que efectivamente hacía gracias a las indicaciones de la praxis (11.57ss.). En conjunto, todos estos detalles revisten al mago de un aura sacral. En PGM VI+II 128-133, otro himno dirigido a Apolo, el mago, quien se re-

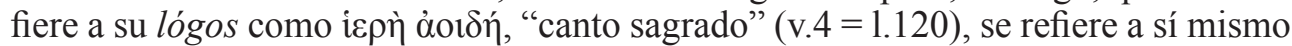

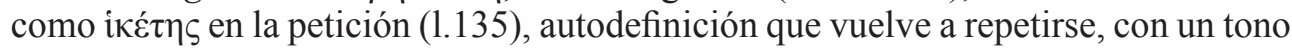
fuertemente rogatorio, en la inscripción de uno de los objetos empleados en el ritual:

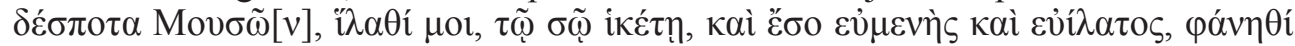
$\mu \mathrm{ol} \kappa \alpha \theta \alpha \rho \tilde{\omega} \tau \tilde{\omega} \pi \rho \circ \sigma \omega ́ \pi \omega$, "señor de las Musas, seme propicio, a mí, tu suplicante, y sé benévolo y propicio, aparécete ante mí con rostro puro" (11.212ss.). Por la praxis

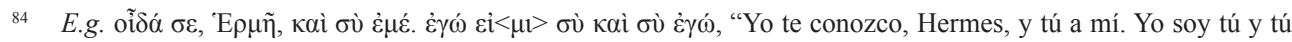
eres yo" (PGM VIII 49-51). Este pasaje es analizado en Chiarini (2016: 96).

85 El texto griego pertenece a la edición de Calvo, vid. Calvo (2008). Traducción: Yo soy el que contigo el mundo entero removió y encontró al gran Osiris, al que conduje encadenado hasta ti. Yo soy el que combatió contigo con los dioses (otros dicen: contra los dioses) hasta que te enseñorearas con este reino; el que cerró las puertas dobles del cielo y calmó a la serpiente invisible, el que levantó el mar, las corrientes y las fuentes de los ríos. Yo tu soldado, estoy vencido por los dioses, precipitado de cabeza causa de una cólera vana. Levanta, te lo ruego, a tu amigo. (Traducción de Calvo, op.cit.)

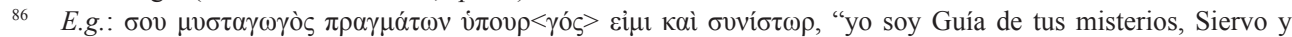
Testigo", ( $P G M$ IV 2249). Al margen del hecho de que los magos se definan a menudo en sus escritos como

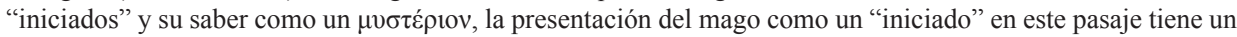
carácter argumental, ya que se utiliza para legitimar la autoridad del mismo para hacerle una petición a la diosa.

87 Esta numeración, que no se encuentra en $P G M$ ni Betz $\left(1992^{2}\right)$, donde los papiros VI y II figuran como papiros distintos, se debe al reciente descubrimiento de que no se trata de dos papiros, sino dos fragmentos de un mismo papiro, vid. Chronopoulou (2017). 
(11. 111-149), sabemos que el mago portaba un attrezzo similar al del ejemplo anterior, con corona y ramo adornados, incluso, con vitae de lana reforzando el parecido

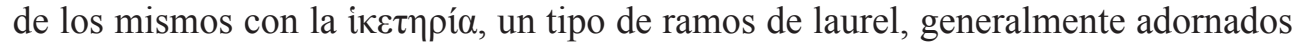
con cintas de lana blanca, característicos del ritual de la súplica (de ahí su nombre) ${ }^{88}$. La búsqueda de esta "apariencia" religiosa podía incluso determinar la construcción del discurso por entero, como sucede en el caso de la imitación del peán y sus estilemas en los lógoi mágicos dirigido a Apolo ${ }^{89}$.

La caracterización del mago en estos lógoi como un sacerdote o suplicante no tiene que confundirse con la consideración de los magos como "sacerdotes" o "iniciados" de su propia forma de culto. Estos lógoi, a pesar del tono rogatorio, la forma hímnica y la presentación piadosa del mago, tenían una finalidad oracular de carácter mágico, es decir, solicitaban al dios que se presentase ante el mago y vaticinase para él, con un carácter privado, fuera del contexto de sus templos o santuarios; igualmente, las ramas de laurel que tan piadosamente sostiene el mago, resultan en ambos casos estar inscritas con palabras y símbolos mágicos. La intención y naturaleza mágica de estas invocaciones resulta más clara en un pasaje hímnico emparentado con los aquí mencionados, también dirigido a Apolo, donde el mago, que "se viste

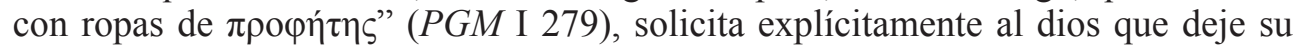

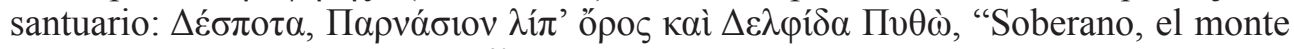
Parnaso deja y la délfica Pitho" ${ }^{90}$; el ramo que sujeta, inscrito con símbolos mágicos como en los dos ejemplos anteriores, es en realidad un amuleto contra el propio dios (o para retener al dios, no queda claro 11.270-276). Es decir, el lenguaje, la actitud y el atrezzo piadoso del mago en estos lógoi son artificiales e intencionados, recursos todos ellos de los que se sirve el practicante de magia para caracterizarse ante el dios como un hombre piadoso con el fin de atraerlo a su práctica. Por lo tanto, más que retóricos, podríamos calificar de oratorios, puesto que trascienden de la mera construcción del discurso a la puesta en escena.

(c) Por último, aunque no menos importantes, están los argumentos del tipo do ut $d e s^{91}$, que se encuentran en la plegaria del mundo griego desde sus primeros textos ${ }^{92}$

88 Vid. ThesCRA III, p.197. Sabemos, no obstante, que estos también se empleaban en otros contextos rituales, como las fiestas dafneforicas, donde los llevaban miembros de los coros apolíneos, vid. Pi. fr. 94 Snell-Maehler = B7 Rutherford; Maced. Paean 1-4 Bremer-Furley. Por la abundancia de testimonios literarios e iconográficos del empleo de estos ramos en distintos contextos, Pellizer (ThesCRA III, p.127) considera que este objeto se llevó más allá de su función instrumental ritual y se generalizó, convirtiéndose en un símbolo de la actitud de la súplica, funcionando «come una rosta di epiteto figurativo». Este empleo de un mismo objeto ritual en prácticas no vinculadas entre sí ha sido explicado por Gernet (1976: 233) como un intento de conseguir la asistencia o ayuda del dios por medio de símbolos que se han demostrado eficaces en contextos análogos y que se emplean como garantía o refuerzo del rito.

89 Sobre ello me permito remitir a un trabajo anterior, vid. Blanco (2013b).

90 h.Mag. VIII 1-2 = PGM I 297-298. Se trata de dos versos hexámetros probablemente pertenecientes a otra composición, por su carácter truncado y falta de conexión con el contexto, que fueron recogidos en un lógos más amplio como parte de la invocación.

91 Este argumento puede presentarse en forma de distintas variantes. Las principales son da quia dedi "da, porque yo te di": e.g. "si alguna vez he techado tu amable templo o alguna vez en tu honor quemé pingües muslos de toros y cabras, cúmpleme ahora este deseo" (Il. I. 39-42); da quia dedisti o fac quia fecisti, "actúa, igual que anteriormente actuaste": e.g. "ya que una vez antes escuchaste mi plegaria, y a mí me honraste e infligiste un grave castigo a la hueste de los aqueos, también ahora cúmpleme este deseo" (Il. I. 453-55); da quia dabo, "da y te daré”: e.g. “¡Augusta Atenea! (...) quiebra la pica de Diomedes y concédeme que caiga de bruces ante las puertas Esceas y en tu honor sacrificaremos en el templo doce terneras" (Il. VI 305-309).

92 Vid. nota precedente. 
y fueron ya criticados en la antigüedad por no asentarse sobre la piedad sino sobre una negociación con la divinidad en base a un contrato: "yo te rindo culto para que tú me des cuando lo pida". Es decir, la práctica religiosa tendría, para los sujetos que empleaban este tipo de recurso, una finalidad práctica, un interés egoísta que conlleva una cierta obligación para la divinidad. Por ello, resultó un recurso que se adaptaba muy bien a la personalidad "interesada" de la magia. En su variante da quia dedi se encuentra, por ejemplo, en PGM VI+II 29-38, en un lógos hexamétrico que aprovecha, además, uno de los ejemplos más conocidos de este tipo de plegaria en la cultura griega: la plegaria que dirige Crises a Apolo en el canto I de la Ilíada (Il. I 37-41, 451-455). Esta reza «si alguna vez de gratas ofrendas tu altar colmé, o si alguna vez en tu honor pingües muslos quemé de toros y de cabras, concédeme este deseo», y basa su alegación en actos rituales que efectivamente el suplicante original -Crises- realizó. Empleada en el contexto de un lógos mágico, el mago, además de asumir la identidad de su emisor original, que era un sacerdote - con lo que enlazamos con el recurso anterior-, se atribuye unos actos rituales que en realidad no ha realizado - vid. en el apartado 2.2.b, la autoatribución de acciones míticas en beneficio del dios invocado-, adquiriendo así este argumento una dimensión falaz que reclama un servicio divino a cambio de un acto cultual que nunca se ha realizado o realizará, aunque el mago no duda que el dios le crea, lo que entronca, a su vez, con la ingenuidad de las divinidades en los textos mágicos. A este argumento se superpondría, además, la eficacia de esta oración en su contexto original: la Ilíada describe la inmediata reacción de Apolo a las palabras de Crises (Il. I.43ss.; 456ss.). Como en la historiola, la eficacia en el contexto narrativo original permanece en estos versos como una cualidad inherente y se perpetúa en todo nuevo contexto de reutilización, de forma que Apolo accederá a la petición del mago igual que accedió a la petición de Crises.

\section{La sobreacumulación de recursos}

Quiero cerrar este estudio ilustrando con un ejemplo un rasgo sobre el que se ha venido insistiendo desde el comienzo: en el discurso mágico, los procedimientos que se han ido señalando no aparecen de forma independiente, aislada, sino combinados con muchos otros en un ejercicio de sobreacumulación. El discurso mágico resulta ser por ello un sistema complejo en el que las diferentes figuras y argumentos se refuerzan entre sí.

Para ello he escogido uno de los textos en la que esta -la sobreacumulación- es, quizás, más “exagerada”: el h.Mag. XVII (PGM IV 2242-2417), un hechizo de más de cien versos en trímetros yámbicos del que reproduzco aquí tan sólo el pasaje inicial (vv.1-21) a modo de ejemplo:

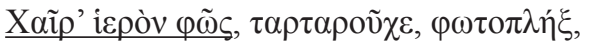

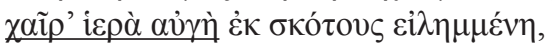
$\rightarrow$ Repetición simple en variatio

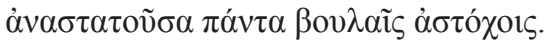

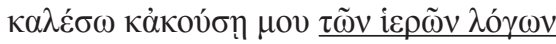

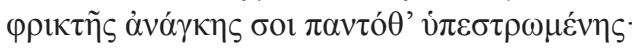

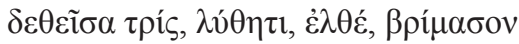

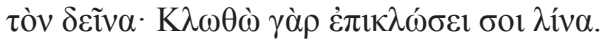




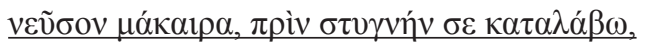

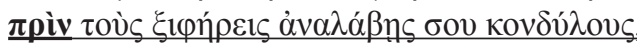

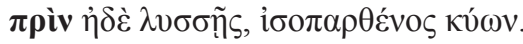

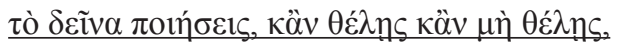

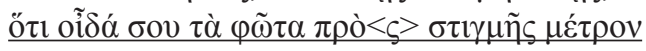

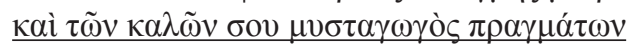

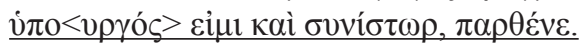

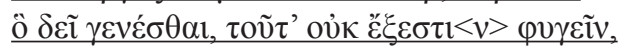

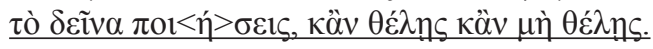

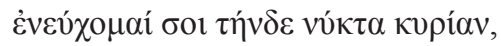

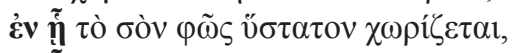

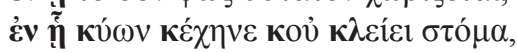

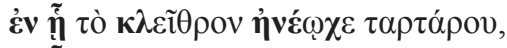

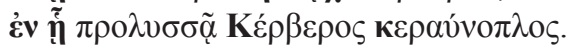
$(\ldots)^{93}$

$\rightarrow$ Amenaza en cláusulas de estructura paralelística en anáfora.

$\rightarrow$ Coacción

$\rightarrow$ Argumento de autoridad

$\rightarrow$ Presentación prestigiosa (argumento de autoridad)

En esta plegaria mágica, que pertenece al ámbito de la magia agresiva como se

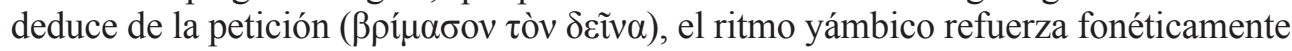
unos versos en los que las figuras poéticas se agolpan para lograr la eficacia "mágica" de la salmodia, mientras se encadenan amenazas, argumentos retóricos, religiosos y argumentos de autoridad que apelan a la credulidad divina en la palabra del mago al mismo tiempo que este ensalza la omnipotencia de la diosa. Los motivos de esta hipercaracterización retórica del discurso mágico son diversos: por un lado actúa la obsesión de la magia por asegurar y garantizar la eficacia de la práctica; por otro, la ausencia de neutralización. Este texto ilustra bien cómo los recursos examinados no son mutuamente excluyentes; el mago no ve contradicción en rogar a la diosa tras haberla amenazado, ni en calificar como ípó $\varsigma$ una plegaria coactiva de magia agresiva.

\section{Conclusiones}

En su examen comparativo de la plegaria mágica y la plegaria religiosa griega, F. Graf concluía "coercion is not omnipresent in the spells and (magical) prayers in a manner that would justify taking it as a-or the-differentia specifica or magic from religion" 94 . Efectivamente, a lo largo de este examen he querido mostrar que, en el contexto del diálogo con la divinidad, la coerción es tan sólo uno más de los recursos de los que se sirvieron los magos greco-egipcios para conseguir que la divinidad cumpliera lo solicitado. La total ausencia, de hecho, de coerción en algunos textos

93 Traducción: Saludos, sagrada luz, señora del Tártaro, que hieres con tu luz,/ saludos, sagrado brillo /sustraído de las tinieblas, que lo disturbas todo con decisiones incomprensibles./Te llamaré y escucharás mi sagrada invocación/ porque la estremecedora necesidad está sometida a ti en todo momento./ Tres veces ligada, libérate, ven, enfurécete con [nombre de la víctima]. Kloto hilará tu hilo. Accede, bienaventurada, antes de que, torva, te domine,/ antes de que levantes tus puños armados de espadas,/ antes de que te enfurezcas, perra con aspecto de muchacha./ [Tal] lo harás, tanto si quieres como si no quieres,/ porque conozco tu luz hasta la medida de un punto y de tus hermosos misterios soy Guía, Siervo y Testigo, doncella./ Lo que tiene que ocurrir, de esto no te es posible huir,/ [tal] lo harás, tanto si quieres como si no quieres./ Te ruego en esta noche decisiva/ en la que tu luz se aleja la última,/ en la que el perro abre y no cierra sus fauces,/ en la que la cerradura del Tártaro se han abierto,/ en la que Cerbero armado con el rayo está rabioso,/ (...).

$94 \operatorname{Graf}(1991:$ 194). 
hace que se mantenga abierta la discusión sobre su pertenencia o no al ámbito mágico, como ocurre con las denominadas "judicial prayers"

Se ha visto también que, en el plano retórico, la plegaria mágica, ya sea en prosa o en verso, y los hechizos muestran la misma tendencia a la inclusión y sincretismo que presenta la magia para la asimilación de divinidades, admitiendo cualquier recurso poético, retórico o religioso, griego, egipcio o semítico, que se hubiera demostrado eficaz en su contexto de origen o que pudiera ser provechoso para los intereses del mago. Esta tendencia, unida a la sobreacumulación de recursos, tiene como resultado un discurso con lo divino -hechizos, himnos, plegarias o como queramos llamarlos- extremadamente complejo desde el punto de vista retórico, en el que los recursos para lograr su eficacia y el cumplimiento de la petición abarcan la totalidad de las dimensiones del texto: ritmo, fonética, estructura y contenido, yendo incluso más allá en el caso de los recursos basados en el poder performativo de la palabra.

Pero no se trata únicamente de un proceso de "apropiación"; los recursos se adaptan al nuevo contexto de utilización experimentando una especificación particular y característica de su empleo en el contexto del diálogo mágico, surgiendo formas y

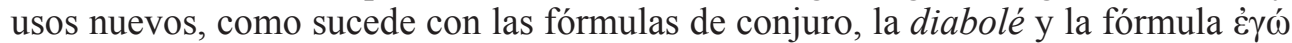
cỉu, que conviven a su vez con recursos comunes a otras formas de diálogo con la divinidad, como la religión y, sobre todo, su práctica popular, un ámbito en el que los límites entre magia y religión se neutralizan aún más si cabe por la extensa difusión de recursos como la simpatía. La amenaza y la historiola, que desde un punto de vista helenocéntrico parecen extraños, se encuentran en el diálogo religioso egipcio. Es decir, en el discurso con la divinidad la magia greco-egipcia innovó, pero no inventó, sirviéndose de un amplio acervo de procedimientos, en consonancia con la propia naturaleza sincrética de la magia, a través del cual se integró en la rica herencia cultural del Mediterráneo de la que ella misma era producto.

\section{Bibliografía}

Audollent, Auguste (1904), Defixionum tabellae quotquot innotuerunt, París.

Austin, John L. (1962), How to do things with words, Oxford

Bergman, Jan (1968), Ich bin Isis: Studien zum memphitischen Hintergrund der griechischen Isisaretalogien. Uppsala.

95 Se trata de un tipo de plegarias, cuyo nombre se debe a H. Versnel (1991b), en las que una persona se presentaba ante la divinidad como suplicante pidiendo justicia por un agravio. Se trata de una categoría compleja de textos porque la justicia debía tomar la forma de un castigo divino, por lo que no son muy distintas, en cuanto a la finalidad, de una maldición, pero sí en el tono (siempre rogatorio) y la motivación, legítima (es decir, no es ficticia como en la diabolé). En estas plegarias, aunque no hay coerción (que está totalmente ausente), sí hay, no obstante, reminiscencias de fórmulas de maldición e, incluso, parecidos formales con las defixiones. También la forma de justificar la petición, mediante la insistencia en la impiedad y perversidad del infractor en contraposición a la piedad del suplicante con el fin de incidir en la injusticia de un acto y en la necesidad de castigo, hemos visto que se empleó en discursos claramente mágicos. Por ello, la crítica está dividida: Versnel (1991b: 80-81) las considera "a borderline kind of prayer", no completamente mágicas, pero tampoco religiosas debido a las similitudes con algunos rasgos mágicos que he mencionado; Faraone (2001b: 81.), por su parte, no duda en considerarlas mágicas y se refiere a ellas como "revenge curses". Desde mi punto de vista, como ya apunté en un trabajo anterior (Blanco-Chronopoulou, 2018, p. 2) la falta de beneficio para el suplicante, que tan sólo obtiene "justicia", es determinante para considerarlas no mágicas. 
Bernabé, Alberto (2003), «Las ephesia grammata: génesis de una fórmula mágica», MHNH 3: 5-28.

Betz, Hans Dieter (1991), «Magic and Mystery in the Greek Magical Papyri», en Faraone, Ch. - Obbink, D. (eds.): 244-259.

Betz, Hans Dieter $\left(1992^{2}\right)$, The Greek Magical Papyri in Translation. Including the Demotic Spells, Chicago - London.

Blanco, Miriam - Chronopoulou, Eleni (2018), «The Irresistible Attraction of Purity: Accusations of religious transgression in magical texts from Late Antiquity», en Peels, S. - Carbon, J.M. (eds.).

Blanco, Miriam (2013a), «El embarazo infamante de Selene: una calumnia verosímil», en Suárez de la Torre, E. y Pérez Jiménez, A. (eds.), Mito y magia en Grecia y Roma (MHNH Suppl. 1), Barcelona: 213-222.

Blanco, Miriam (2013b), «The magicians who sang to the gods», en García, J. V. and A. Ruiz (eds.), Poetic Language and Religion in Greece and Rome, Newcastle: 278-285

Bremmer, Jan (1999), «The birth of term magic», ZPE 126: 1-12

Bremmer, Jan (2002), «Appendix: Magic and Religion», en Bremmer, J. - Veenstra, J.R. (eds.), The Metamorphosis of Magic from Late Antiquity to the Early Modern Period, Leuven-Paris: 265-269.

Calvo, José Luis (2008), «Dos himnos a Set-Tifón en la colección PGM», MHNH 8: 232-242.

Carey, Chris (2004), «The rhetoric of diabolé», publicación online $<\mathrm{http}$ ://eprints.ucl.ac.uk/ archive/00003281/>

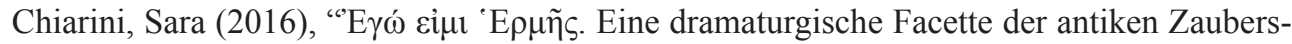
prache", Tyche 31: 75-102.

Chronopoulou, Eleni (2015), «El oficio peligroso del mago», en Suárez, E. - Blanco, M. Chronopoulou, E . (eds.), Los papiros mágicos griegos: entre lo sublime y lo cotidiano, Madrid: 13-30.

Chronopoulou, Eleni (2017), “PGM VI: A Lost part of PGM II”, SO 91: 1-8.

Daniel, Robert W. - Maltomini, Franco (1990- 1992), Supplementum Magicum, 2.Vol. Opladen.

Daniel, Robert W. (1988), «A note on the Philinna's Papyrus», ZPE 73: 306.

De Haro, M. (ed.), (2015), Écrire la magie and l'antiquité, Liège.

Dornseiff, Franz (reimp. 1998), Das Alphabet in Mystik und Magie, Leipzig. $1^{\text {a }}$ ed. 1926.

Eitrem, Samson (1924), «Die Rituelle $\triangle \mathrm{IABO} \Lambda \mathrm{H} »$, SO 2: 43-58.

Eliade, Mircea (1963), Myth and Reality, New York.

Faraone, Ch. - Obbink, D. (eds.), (1991), Magika Hiera: Ancient Greek Magic and Religion, New York-Oxford.

Faraone, Christofer (1991), «The agonistic context of early Greek binding expells», en Faraone, Ch. - Obbink, D. (eds.): 3-32.

Faraone, Christofer $\left(2001^{2} \mathrm{a}\right)$, «The Mystodokos and the Dark-Eyed Maidens: Multicultural Influences on a Late-Hellenistic Incantation», en Meyer, M. - Mirecki, P. (eds.): 297-333.

Faraone, Christofer (2001b), Ancient Greek Love Magic, Harvard University Press.

Faraone, Christofer (2009), «Stopping Evil, Pain, Anger and Blood: the Ancient Greek Tradition of Protective Iambic Incantations», GRBS 49: 227-255.

Faraone, Christofer (2011), "Hexametrical Incantations as Oral and Written Phenomena», en Lardinois, A. P. et alii (eds.), Sacred Words: Orality, Literacy and Religion, LeidenBoston: 189-204.

Fournier, Michael (2013), «Gorgias on Magic», en Magic, Ritual, and Witchcraft 8: 119-131. Fowler, Robert L. (1995), «Greek Magic, Greek Religion», ICS 20: 1-22. 
Frankfurter, David $\left(2001^{2}\right)$, «Narrating Power: The Theory and Practice of the Magical Historiola in Ritual Spells», en Meyer, M. y Mirecki, P. (eds.): 457-476.

Gager, John G. (1972), Moses in Greco-Roman Paganism, Nashville.

Gager, John G. (1994), «Moses the Magician: Hero of an Ancient Counter-Culture?», Helios 21: 179-188.

Gager, John G. (1992), Curse Tablets and Binding Spells from the Ancient World. Oxford.

Garcia Teijeiro, Manuel (1987), «Retórica, oratoria y magia», en Morocho Gayo, G. (ed.), Estudios de Drama y Retórica en Grecia y en Roma, León: 143-154.

Garcia Teijeiro, Manuel (1989), «Recursos fonéticos y recursos gráficos en los textos mágicos griegos», RSEL 19: 233-250.

Garcia Teijeiro, Manuel (1992), «Langage orgiastique et glossolalia», Kernos 5: 59-69.

Garcia Teijeiro, Manuel (1996), «La lengua de los documentos mágicos», en Fernández Delgado, J.A. - Ramos, A. (eds.), Las lenguas de corpus y sus problemas lingüísticos, Salamanca: 151-166.

Gernet, Louis (reimpr. 1976), Anthropologie de la Grèce antique, Paris. $1^{\mathrm{a}} \mathrm{ed} .1882$.

Gignac, F. T. (vol. I 1976, vol.II 1981), A Grammar of the Greek Papyri of the Roman and Byzantine Period, Milán.

Graf, Fritz (1991), «Prayer in Magic and Religious Ritual», en Faraone, C. - Obbink, D. (eds.): 188-213.

Graf, Fritz (2005), «Magical Sacrifice», en R. Hägg - B. Alroth (eds.), Greek Sacrificial Ritual. Olympian and Chthonian, Proceedings of the Sixth International Seminar on Ancient Greek Cult, Göteborg University, 25-27 April 1997, Stockholm: 69-75.

Graf, Fritz (2015), “Magie et écriture: quelques réflexions”, en De Haro, M. (ed.): 227-238.

Heim, Richard (1892), Incantamenta magica graeca latina, Leipzig.

Heredia Correa, Roberto (2003), Apuleyo. Apología, México.

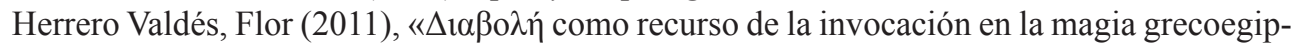
cia», $M H N H$ 11: 305-318.

Johnston, Sarah Iles (2000), «Le sacrifice dans le papyrus magiques», en Moreau, A. - Tupin, J. C. (eds.), La magie, Actes du colloque international de Montpellier, 25-27 Mars 1999, Vol.II: La magie dans l'antiquité tardive, Montpellier: 19-36.

Jordan, D.R. (1988), «A New Reading of a Papyrus Love Charm in the Louvre», ZPE 74: 231-243.

Kotansky, Roy (1994), Greek Magical Amulets. The Inscribed Gold, Silver, Copper, and Bronze Lamellae. Part I: Published Texts of Known Provenance. Opladen.

Kropp, Amina (2010), «How does magical language work? The spells and formulae of the latin defixionum tabellae», en Gordon, R. L. - Marco Simón, F. (eds.), Magical Practice in the Latin West, Leiden-Boston: 357-380.

Levi, Peter (1975), «The prose style of the Magical Papyri», en Proceedings of the XIVth International Congress of Papyrologists, Londres: 211-216.

López Eire, Antonio (1999), «Lectura moderna de la retórica clásica», en Castilla: Estudios de literatura 24: 103-128.

Maas, Paul (1942), «The Philinna Papyrus», JHS 62: 33-38.

Mastrocinque, Attilio. (2003-2007), Sylloge Gemmarum Gnosticarum. (Bollettino di Numismatica, Monografia 8.2.I), 2 Vols., Rome.

Meyer, M. - Mirecki, P. (eds. 2001²), Ancient Magic and Ritual Power, Leiden-New YorkKöln, Brill.

Muñoz Delgado, Luis (2001), Léxico de magia y religión en los papiros mágicos griegos (LMPG), Madrid: CSIC. Disponible como recurso en línea en $<$ http://dge.cchs.csic.es/lmpg/>. 
Norden, Eduard (1913), Agnostos Theos. Leipzig.

Otto, Bernd-Christian (2013), «Towards Historicizing "Magic" in Antiquity», Numen 60: 308-347.

Passeti, Lucia (2015), «Ethical limits of rhetorical exaggeration», comunicación presentada en Europaeum Classics Colloquium: Poetry, Oratory, Rhetoric, Persuassion: the power of word in ancient times, $5^{\text {th }}-7^{\text {th }}$ November 2015, Barcelona.

Peels, Saskia - Carbon, Jan-Mathieu (eds.), (2018), Katharos: Concepts of Purity and Rituals of Purification in the Ancient Greek World. (Kernos, Suppl. 31), Liège.

Pinch, Geraldine (2002), Egyptian Mythology: A Guide to the Gods, Goddesses and Traditions of Ancient Egypt, Oxford.

Preisendanz, K. (1973-1974²) Papyri graecae magicae. Die griechischen zauberpapyri, 2 Vols., Stuttgart. $2^{\mathrm{a}}$. ed. revisada por Henrichs, A.

Preisendanz, Karl (1973-1974²) Papyri graecae magicae. Die griechischen zauberpapyri, 2 Vols., Stuttgart. $2^{\mathrm{a}}$. ed. revisada por Henrichs, A.

Rodríguez Merino, Ángel (2005), Las fórmulas de invocación en los papiros mágicos griegos, Tesis doctoral inédita. Valladolid, Departamento de Filología Clásica, Universidad de Valladolid.

Romilly, Jacqueline (1973), «Gorgias et le pouvoir de la poésie», JHS 93: 155-162.

Romilly, Jacqueline (1975) Magic and rhetoric in ancient Greece, Harvard.

Schweizer, Eduard (1939) Ego eimi, Gottingen.

Searle, John R. - Vanderveken, Daniel (1985), Foundations of Illocutionary Logic, Cambridge.

Suárez, E. -Blanco, M. -Chronopoulou, E. (2016), «A la vez igual y diferente: notas sobre el vocabulario 'religioso' de los textos mágicos griegos», en Calderón, E. y Perea, S. (eds.) Estudios sobre le vocabulario religioso griego, Madrid-Salamanca: 210-233.

Suárez, Emilio (2014a), «Entrelazamientos eróticos», en Martínez Fernández, A. et alii (ed.), Agalma: ofrenda desde la Filología clásica a la Manuel García Teijeiro, Valladolid: 637646.

Suárez, Emilio (2014b), «Pseudoepigraphy and Magic», en Martinez, J. (ed.), Fakes and Forgers of Classical Literature. Ergo decipiatur!, Leiden-Boston: 243-262.

Szepes, E. (1976), « Magic Elements in the prayers of the hellenistic magic papyri», AAntHung 24: 205-225.

Tambiah, Stanley J. (1985), Culture, Thought and Social Action. An Antropological perspective, Cambridge Ma.

, (2005-2012), 8 vols., Los Ángeles.

Thyen, Hartwig (1996), «Ich-Bin-Worte», RAC 17: 47-213.

Versnel, Henk S. (1991b), «Beyond Cursing: The Appeal to Justice in Judicial Prayers», en Faraone, C. - Obbink, D. (eds.): 60-106.

Versnel, Henk S. (1991a), «Some Reflections on the Relationship Magic-Religion», Numen 38: 177-197.

Versnel, Henk S. (2002), «The poetics of the magical charm. An essay in the power of words», en Meyer, M. - Mirecki, P. (eds.), Magic and Ritual in the Ancient World, Leiden-BostonKöln: 105-158.

Waegeman, Maryse (1987), Amulet and Alphabet, Amsterdam.

Wortmann, Dierk (1968), «Neue magische Texte», BJ 168: 56-111.

Zografou, Athanasía (2008), «Prescriptions sacrificielles dans les papyri magiques», en Mehl, V. - Brulé, P. (éds.), Le sacrifice antique. Vestiges, procédures et stratégies, Rennes, pp. 187-203. 
Zografou, Athanasía (2015), «Les Formules d'adjuration dans les Papyrus Magiques», en De Haro, M. (ed.): 267-280.

Zografou, Athanasia (2016), Des dieux maniables. Hécate \& Cronos dans les Papyrus magiques grecs. Paris.

Zografou, Athanasia (2018), «Être pur pour réussir: le conditionnement de l'efficacite rituelle dans les $P G M »$, en Peels, S. - Carbon, J.M. (eds.). 